Cochrane Database of Systematic Reviews

\title{
Endovascular treatment for ruptured abdominal aortic aneurysm
} (Review)

Badger S, Forster R, Blair PH, Ellis P, Kee F, Harkin DW

Badger S, Forster R, Blair PH, Ellis P, Kee F, Harkin DW.

Endovascular treatment for ruptured abdominal aortic aneurysm.

Cochrane Database of Systematic Reviews 2017, Issue 5. Art. No.: CD005261.

DOI: 10.1002/14651858.CD005261.pub4.

www.cochranelibrary.com 
TABLE OF CONTENTS

HEADER 1

ABSTRACT

PLAIN LANGUAGE SUMMARY

SUMMARY OF FINDINGS

BACKGROUND

OBJECTIVES

METHODS

RESULTS

Figure 1.

Figure 2.

Figure 3.

DISCUSSION

AUTHORS' CONCLUSIONS

ACKNOWLEDGEMENTS

REFERENCES

CHARACTERISTICS OF STUDIES

DATA AND ANALYSES

Analysis 1.1. Comparison 1 Emergency endovascular aneurysm repair versus open repair, Outcome 1 Short-term mortality (30day or in-hospital).

Analysis 1.2. Comparison 1 Emergency endovascular aneurysm repair versus open repair, Outcome 2 Major complications - 30day.

Analysis 1.3. Comparison 1 Emergency endovascular aneurysm repair versus open repair, Outcome 3 Complication - Myocardial infarction.

Analysis 1.4. Comparison 1 Emergency endovascular aneurysm repair versus open repair, Outcome 4 Complication - Stroke. ... Analysis 1.5. Comparison 1 Emergency endovascular aneurysm repair versus open repair, Outcome 5 Complication - Cardiac complications (moderate or severe).

Analysis 1.6. Comparison 1 Emergency endovascular aneurysm repair versus open repair, Outcome 6 Complication - Renal complications (moderate or severe).

Analysis 1.7. Comparison 1 Emergency endovascular aneurysm repair versus open repair, Outcome 7 Complication Respiratory failure.

Analysis 1.8. Comparison 1 Emergency endovascular aneurysm repair versus open repair, Outcome 8 Complication - Bowel ischaemia.

Analysis 1.9. Comparison 1 Emergency endovascular aneurysm repair versus open repair, Outcome 9 Complication - Spinal cord ischaemia.

Analysis 1.10. Comparison 1 Emergency endovascular aneurysm repair versus open repair, Outcome 10 Complication Reoperation.

Analysis 1.11. Comparison 1 Emergency endovascular aneurysm repair versus open repair, Outcome 11 Complication Amputation.

Analysis 1.12. Comparison 1 Emergency endovascular aneurysm repair versus open repair, Outcome 12 Mortality - 6 months. .

Analysis 1.13. Comparison 1 Emergency endovascular aneurysm repair versus open repair, Outcome 13 Major complications - 6 months.

Analysis 1.14. Comparison 1 Emergency endovascular aneurysm repair versus open repair, Outcome 14 Complication Reoperation - 6 months.

Analysis 1.15. Comparison 1 Emergency endovascular aneurysm repair versus open repair, Outcome 15 Mortality - 1 year. ..... Analysis 1.16. Comparison 1 Emergency endovascular aneurysm repair versus open repair, Outcome 16 Cost per patient - 30day.

ADDITIONAL TABLES

APPENDICES

FEEDBACK

WHAT'S NEW

HISTORY 
[Intervention Review]

\title{
Endovascular treatment for ruptured abdominal aortic aneurysm
}

\author{
Stephen Badger ${ }^{1}$, Rachel Forster ${ }^{2}$, Paul H Blair ${ }^{3}$, Peter Ellis ${ }^{3}$, Frank Kee ${ }^{4}$, Denis W Harkin 3
}

1Department of Vascular Surgery, Mater Misericordiae University Hospital, Dublin, Ireland. 2Usher Institute of Population Health Sciences and Informatics, University of Edinburgh, Edinburgh, UK. ${ }^{3}$ Belfast Vascular Centre, Royal Victoria Hospital, Belfast, UK. ${ }^{4}$ Centre for Public Health, School of Medicine, Dentistry and Biomedical Sciences, Queen's University Belfast, Belfast, UK

Contact address: Denis W Harkin, Belfast Vascular Centre, Royal Victoria Hospital, Belfast Health \& Social Care Trust, Belfast, Northern Ireland, BT12 6BA, UK. denis.harkin@belfasttrust.hscni.net.

Editorial group: Cochrane Vascular Group.

Publication status and date: Edited (no change to conclusions), comment added to review, published in Issue 6, 2017.

Citation: Badger S, Forster R, Blair PH, Ellis P, Kee F, Harkin DW. Endovascular treatment for ruptured abdominal aortic aneurysm. Cochrane Database of Systematic Reviews 2017, Issue 5. Art. No.: CD005261. DOI: 10.1002/14651858.CD005261.pub4.

Copyright @ 2017 The Cochrane Collaboration. Published by John Wiley \& Sons, Ltd.

\section{A B S T R A C T}

\section{Background}

An abdominal aortic aneurysm (AAA) (pathological enlargement of the aorta) is a condition that can occur as a person ages. It is most commonly seen in men older than 65 years of age. Progressive aneurysm enlargement can lead to rupture and massive internal bleeding, which is fatal unless timely repair can be achieved. Despite improvements in perioperative care, mortality remains high (approximately $50 \%$ ) after conventional open surgical repair. Endovascular aneurysm repair (EVAR), a minimally invasive technique, has been shown to reduce early morbidity and mortality as compared to conventional open surgery for planned AAA repair. More recently emergency endovascular aneurysm repair (eEVAR) has been used successfully to treat ruptured abdominal aortic aneurysm (RAAA), proving that it is feasible in select patients; however, it is unclear if eEVAR will lead to significant improvements in outcomes for these patients or if indeed it can replace conventional open repair as the preferred treatment for this lethal condition. This is an update of the review first published in 2006.

\section{Objectives}

To assess the advantages and disadvantages of emergency endovascular aneurysm repair (eEVAR) in comparison with conventional open surgical repair for the treatment of ruptured abdominal aortic aneurysm (RAAA). This will be determined by comparing the effects of eEVAR and conventional open surgical repair on short-term mortality, major complication rates, aneurysm exclusion (specifically endoleaks in the eEVAR treatment group), and late complications.

\section{Search methods}

For this update the Cochrane Vascular Information Specialist searched the Cochrane Vascular Specialised Register (last searched June 2016), CENTRAL (2016, Issue 5), and trials registries. We also checked reference lists of relevant publications.

\section{Selection criteria}

Randomised controlled trials in which participants with a clinically or radiologically diagnosed RAAA were randomly allocated to eEVAR or conventional open surgical repair.

\section{Data collection and analysis}

Two review authors independently assessed studies identified for potential inclusion for eligibility. Two review authors also independently completed data extraction and quality assessment. Disagreements were resolved through discussion. We performed meta-analysis using fixed-effect models with odds ratios (ORs) and 95\% confidence intervals ( $\mathrm{Cls}$ ) for dichotomous data and mean differences with $95 \% \mathrm{Cls}$ for continuous data. 


\section{Main results}

We included four randomised controlled trials in this review. A total of 868 participants with a clinical or radiological diagnosis of RAAA were randomised to receive either eEVAR or open surgical repair. Overall risk of bias was low, but we considered one study that performed randomisation in blocks by week and performed no allocation concealment and no blinding to be at high risk of selection bias. Another study did not adequately report random sequence generation, putting it at risk of selection bias, and two studies were underpowered. There was no clear evidence to support a difference between the two interventions for 30-day (or in-hospital) mortality (OR 0.88 , 95\% $\mathrm{Cl} 0.66$ to 1.16; moderate-quality evidence). There were a total of 44 endoleak events in 128 participants from three studies (low-quality evidence). Thirty-day complication outcomes (myocardial infarction, stroke, composite cardiac complications, renal complications, severe bowel ischaemia, spinal cord ischaemia, reoperation, amputation, and respiratory failure) were reported in between one and three studies, therefore we were unable to draw a robust conclusion. We downgraded the quality of the evidence for myocardial infarction, renal complications, and respiratory failure due to imprecision, inconsistency, and risk of bias. Odds ratios for complications outcomes were OR 2.38 (95\% Cl 0.34 to 16.53 ; 139 participants; 2 studies; low-quality evidence) for myocardial infarction; OR 1.07 (95\% Cl 0.21 to 5.42; 255 participants; 3 studies; low-quality evidence) for renal complications; and OR 3.62 (95\% Cl 0.14 to 95.78 ; 32 participants; 1 study; lowquality evidence) for respiratory failure. There was low-quality evidence of a reduction in bowel ischaemia in the eEVAR treatment group, but very few events were reported (OR $0.37,95 \% \mathrm{Cl} 0.14$ to 0.94$)$, and we downgraded the evidence due to imprecision and risk of bias. Six-month and one-year outcomes were evaluated in three studies, but only results from a single study could be used for each outcome, which showed no clear evidence of a difference between the interventions. We rated six-month mortality evidence as of moderate quality due to imprecision (OR $0.89,95 \% \mathrm{Cl} 0.40$ to $1.98 ; 116$ participants).

\section{Authors' conclusions}

The conclusions of this review are currently limited by the paucity of data. We found from the data available moderate-quality evidence suggesting there is no difference in 30-day mortality between eEVAR and open repair. Not enough information was provided for complications for us to make a well-informed conclusion, although it is possible that eEVAR is associated with a reduction in bowel ischaemia. Long-term data were lacking for both survival and late complications. More high-quality randomised controlled trials comparing eEVAR and open repair for the treatment of RAAA are needed to better understand if one method is superior to the other, or if there is no difference between the methods on relevant outcomes.

\section{PLAIN LANGUAGE SUMMARY}

\section{Endovascular treatment for ruptured abdominal aortic aneurysm}

\section{Background}

The abdominal aorta is the main artery supplying blood to the lower part of the body. An abnormal ballooning and weakening of the wall of the aorta (aortic aneurysm) can occur with age, particularly in older men. An aneurysm may progressively enlarge without obvious symptoms, yet it is potentially lethal as it can burst (rupture), causing massive internal bleeding. Death is inevitable unless the bleeding can be stopped and blood flow to the lower body promptly restored. Until recently this required an open operation (laparotomy) to clamp the abdominal aorta and replace the segment of the aorta with a synthetic artery tube-graft. Many patients do not survive this major operation due to the effects of massive bleeding or failure of vital organs, such as the heart, lungs, and kidneys, despite improvements in the surgical technique and care of the critically ill patient.

Endovascular treatment, a minimally invasive technique, allows the surgeon to pass a stent graft through the blood vessels from the groin to the site of rupture, where it is positioned and attached to the healthy artery above and below the aneurysm to stop bleeding and form a new channel for blood flow. This technique is successful in suitable patients for the planned treatment of non-ruptured aneurysms and can reduce early postoperative complications and deaths.

\section{Study characteristics and key results}

The present review looked at the available evidence for endovascular repair effectiveness compared with open surgery for ruptured aneurysms. We included four studies with a total of 868 participants. Risk of bias was generally low, but one study was at high risk of selection bias due to their use of the block method of randomisation; one study did not adequately report randomisation methods; and two studies may not have included a sufficient number of participants to adequately answer the questions posed by the studies. We found that from the data currently available there appears to be no difference in death within 30 days of the procedure between endovascular repair and open repair. Endoleaks were reported in 44 participants from three studies. The data on complications (myocardial infarction, stroke, combined cardiac complications, renal complications, spinal cord ischaemia, reoperation, amputation, and respiratory failure) are not robust enough at this point to make any strong conclusions on superiority of either repair technique, but emergency endovascular aneurysm repair (eEVAR) may be associated with a lower risk of bowel ischaemia. No robust conclusion can be made on outcomes at six months or one year. More studies are needed to better understand whether or not one of the aneurysm repair techniques, endovascular or open surgical, is superior based on patient outcomes.

\section{Quality of the evidence}


We found from the data available moderate-quality evidence suggesting there is no difference in 30-day mortality between eEVAR and open repair. Not enough information was provided for complications for us to make a well-informed conclusion, although it is possible that eEVAR is associated with a reduction in bowel ischaemia. We downgraded the quality of the evidence as some studies contained too few participants, not all studies reported on all complication outcomes, and the number of complications occurring between studies varied substantially. 


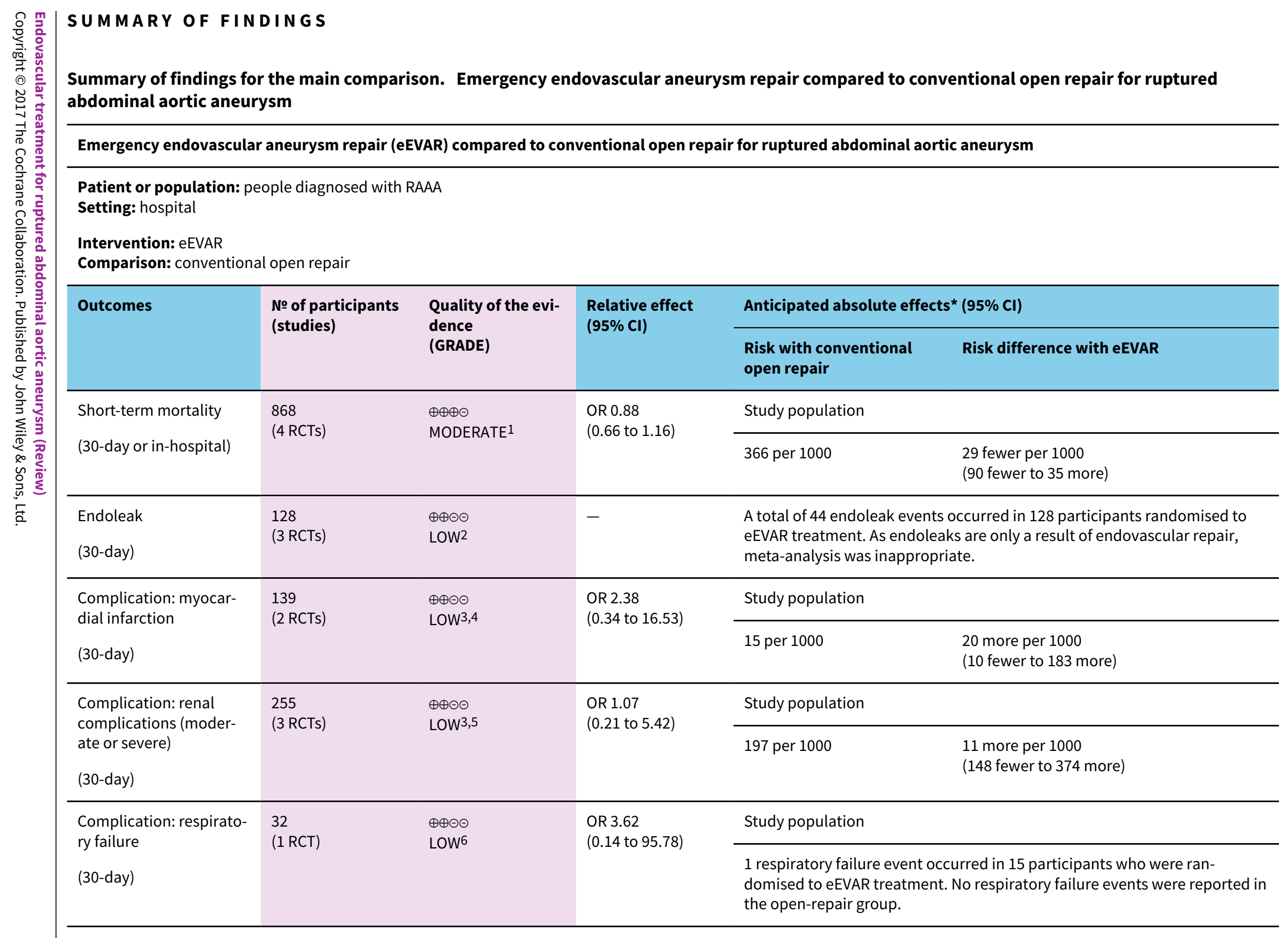




\begin{tabular}{|c|c|c|c|c|c|c|}
\hline 웅 흥 & Complication: bowel is- & \multirow{2}{*}{$\begin{array}{l}223 \\
(2 \mathrm{RCTs})\end{array}$} & \multirow{2}{*}{$\begin{array}{l}\oplus \oplus \ominus \ominus \\
\text { LOW }^{3}, 4\end{array}$} & \multirow{2}{*}{$\begin{array}{l}\text { OR } 0.37 \\
(0.14 \text { to } 0.94)\end{array}$} & \multicolumn{2}{|c|}{ Study population } \\
\hline 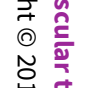 & (30-day) & & & & 145 per 1000 & $\begin{array}{l}86 \text { fewer per } 1000 \\
\text { (122 fewer to } 8 \text { fewer) }\end{array}$ \\
\hline 3 & Mortality & 116 & $\oplus \oplus \oplus \ominus$ & OR 0.89 & Study popula & \\
\hline 产 & (6 months) & & & & 305 per 1000 & $\begin{array}{l}24 \text { fewer per } 1000 \\
\text { (156 fewer to } 160 \text { more) }\end{array}$ \\
\hline 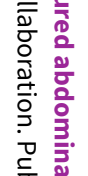 & $\begin{array}{l}\text { *We calculated the assur } \\
\text { events divided by total } n \\
\text { dence interval) is based } \\
\mathrm{Cl} \text { : confidence interval; }\end{array}$ & $\begin{array}{l}\text { d risk of } t \\
\text { nber of pa } \\
\text { the assun } \\
\text { IAR: emer }\end{array}$ & $\begin{array}{l}\text { nal open-repai } \\
\text { he convention } \\
\text { comparison } \\
\text { ascular aneury }\end{array}$ & $\begin{array}{l}\text { rom the averag } \\
\text { repair group in } \\
d \text { the relative } \\
\text { ir; OR: odds rat }\end{array}$ & $\begin{array}{l}\text { in the conventio } \\
d \text { in the meta-an } \\
\text { of the interventic } \\
\text { AA: ruptured abc }\end{array}$ & $\begin{array}{l}\text { group (i.e. the number of participants with } \\
\text { in the intervention group (and its } 95 \% \text { confi- } \\
\mathrm{CI} \text { ). } \\
\text { neurysm; RCT: randomised controlled trial }\end{array}$ \\
\hline 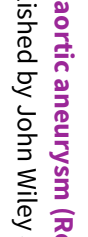 & $\begin{array}{l}\text { GRADE Working Group } \\
\text { High quality: We are ver } \\
\text { Moderate quality: We a } \\
\text { stantially different. } \\
\text { Low quality: Our confid } \\
\text { Very low quality: We ha }\end{array}$ & $\begin{array}{l}\text { Ides of ev } \\
\text { onfident } \\
\text { noderate } \\
\text { ce in the } € \\
\text { very little }\end{array}$ & $\begin{array}{l}\text { effect lies clos } \\
\text { the effect est } \\
\text { e is limited: Th } \\
\text { the effect est }\end{array}$ & $\begin{array}{l}\text { of the estimate } \\
\text { he true effect is } \\
\text { fect may be sub } \\
\text { he true effect is }\end{array}$ & $\begin{array}{l}\text { o be close to th } \\
\text { lly different fro } \\
\text { o be substantia }\end{array}$ & $\begin{array}{l}\text { e effect, but there is a possibility that it is sub- } \\
\text { of the effect. } \\
n \text { the estimate of effect. }\end{array}$ \\
\hline
\end{tabular}

1Downgraded by one level due to imprecision: two of the three studies included in this outcome were underpowered to report on this outcome, as calculated by the study authors. 2Downgraded by two levels due to inconsistency: event values varied greatly between studies, resulting in heterogeneity.

3Downgraded by one level due to imprecision: the outcome analysis included few participants or events, or both.

4Downgraded by one level due to risk of bias as a result of inadequate random sequence generation and allocation concealment within the ECAR study, which contributed the majority of participants within this outcome.

5Downgraded by one level due to inconsistency: event values varied between studies.

6Downgraded by two levels due to very serious imprecision: only a single event was reported in the eEVAR group. 


\section{B A C K G R O U N D}

\section{Description of the condition}

Abdominal aortic aneurysm (AAA), the pathological enlargement of the main artery in the abdomen, affects around $1.34 \%$ of men in England (Jacomelli 2016). The prevalence of AAA has been declining, which is independent of participant selection criteria and reflects better cardiovascular risk profiling and management in the overall population (Conway 2012; UK NAAASP). This is also seen elsewhere, with 2.2\% prevalence in Sweden and 3.3\% in Denmark (Svensjö 2011; Søgaard 2012), due to reduced risk factors, in particular the rate of smoking (Svensjö 2011). The prevalence of AAA in men is approximately three times greater than in women, and the incidence increases with advancing age (Scott 1991; Scott 1995). The cause of AAA is unknown, but its development is associated with many of the cardiovascular risk factors that predispose a person to atherosclerosis and arterial occlusive disease, perhaps most importantly tobacco smoking (Lederle 1997; Wilmink 1999). Genetic factors are also important, as the risk of aneurysm development is significantly greater in relatives of those with a diagnosed AAA (Powell 2003; van Vlijmen 2002). Unfortunately, many aneurysms progressively enlarge without overt symptoms, presenting only when the aneurysm ruptures, a catastrophic event causing massive internal bleeding that results in death in the majority of those affected.

The extremely high mortality rate from ruptured AAA (RAAA) is $80 \%$, accounting for $2 \%$ of total deaths (Gorham 2004; Nordon 2011; Veith 2003). For those at risk of RAAA, the current in-hospital mortality rates in England are around $65 \%$, and a postoperative mortality rate of $41.65 \%$ (Karthikesalingam 2014). Detailed risk analysis and scoring systems have been shown to predict nonsurvivors in certain groups, but individual patient outcomes cannot be accurately predicted. Clinicians have been reticent to rigidly apply these scoring systems, as to do so would serve to preclude most patients with RAAA from surgical repair, condemning them to certain death (Alsac 2005; Korhonen 2004; Neary 2003). It is also now clear that those people who undergo successful open repair of RAAA enjoy a postoperative quality of life similar to the general population (Hinterseher 2004; Tambyraja 2004). Indeed, the longterm survival of RAAA patients after successful repair is the same as for elective repair patients (Mani 2009).

Randomised controlled trials and a Cochrane review have shown that mortality can be reduced by mass population ultrasound screening in men, with early detection and intervention preventing future rupture and aneurysm-related mortality (Ashton 2002; Cosford 2007; Norman 2004). The risk of aneurysm rupture has been shown to be proportional to aneurysm size, with aneurysms measuring less than $5.4 \mathrm{~cm}$ having an annual rupture rate of approximately $1 \%$, whereas those greater than $7.0 \mathrm{~cm}$ in diameter have an annual rupture rate of $32.5 \%$ (Gorham 2004). The UK Small Aneurysm Trial has shown that, in general, people benefit from aneurysm repair when the maximum aneurysm diameter exceeds $5.5 \mathrm{~cm}$, at which stage the risk of spontaneous rupture exceeds the risks of conventional open surgical repair (Greenhalgh 1998). In addition, two randomised controlled trials showed no difference in outcome in participants that received intervention of small aneurysms (less than $5.5 \mathrm{~cm}$ ) compared with participants that received surveillance at that size (CAESAR Trial; PIVOTAL Trial). With the prevalence of AAA much lower in women, there is less robust data regarding the ideal size of aneurysm for treatment, but it is currently recommended that women receive intervention at $5 \mathrm{~cm}$, which is $5 \mathrm{~mm}$ smaller than that which is recommended for men (Moll 2011).

\section{Description of the intervention}

Historically, conventional open surgical repair was the only effective treatment for AAA, which involved open surgical exposure of the aorta and replacement of the aneurysm with a synthetic tube-graft. This complex major operation carries a significant morbidity and mortality due to the combined effects of surgical exposure, haemorrhage, and aortic clamping with related lower body ischaemia-reperfusion injury. However, with improvements in patient selection and perioperative care, excellent results can now be achieved with open repair; some specialist centres report mortality rates of less than $2 \%$, and surgeons in non-specialist units achieve mortality rates of $5 \%$ to $8 \%$ (Gorham 2004; Greenhalgh 1998; Veith 2003).

In the last two decades this approach to treatment of patients with AAA has been challenged by the arrival of endovascular aneurysm repair (EVAR), a minimally-invasive technique. The EVAR technique was introduced to Western surgical practice by Parodi in 1991 (Parodi 1991). He described the placement of a homemade, material-covered metal stent across an abdominal aneurysm to exclude this from the circulation and to form a new channel for blood flow. The stent is delivered to the aorta from a remote accessible vessel such as the femoral artery at the groin. Since this seminal report, outcomes have progressively improved with significant advancements in commercial stent design, delivery, and the implantation technique (Harris 2005; Lee 2004; Thomas 2005). Since the inception of the EVAR technique, many specialised vascular surgery centres have adopted its use in the elective treatment of AAA, where its use has contributed to a reduction in early postoperative morbidity and mortality (EVAR 2004; Prinssen 2004). In many countries it has now become established in most centres as the primary mode of aneurysm repair (Mani 2011). A recent Cochrane review showed improved short-term mortality for EVAR compared with open repair, but no difference for mediumand long-term mortality (Paravastu 2014).

\section{How the intervention might work}

Modern aortic stent grafts are available in a range of sizes and can be custom designed. The addition of fenestrations and side-branches can adapt the stent to suit encountered difficult anatomical variations. These modular devices are most commonly delivered remotely by open exposure of the femoral arteries and are broadly described as the aorto-uni-iliac (single-lumen) graft and aortobi-iliac (bifurcated-lumen) graft. The minimally invasive nature of this technique allows it to be performed under regional or even local anaesthesia rather than general anaesthesia. In recent years minimally invasive percutaneous deployment of stent under local anaesthesia has become popular, and routine in some centres. This increases the availability of the technique to those patients with significant concomitant medical disease who may otherwise have been considered unfit for surgery (Lachat 2002; Veith 2003).

Two large prospective randomised controlled trials have compared EVAR with conventional open repair for the treatment of large AAAs and have shown significant reductions in early complications and mortality (EVAR 2004; Prinssen 2004). However, whilst endovascular repair for unruptured AAA clearly has a role in 
'healthy' patients, these trials have also reinforced the knowledge that open repair is a successful technique and will remain a common form of treatment for patients presenting with a large AAA for whom EVAR is unsuitable on anatomical grounds or due to other factors (EVAR 2004; EVAR 2005). Long-term results from the EVAR 1 trial revealed later ruptures in the EVAR group, and therefore short-term benefit to EVAR, but no long-term difference in all-cause mortality (Brown 2012). Furthermore, it is now clear that those patients who are unfit for open surgical repair can expect such a high mortality rate from their comorbid disease that even successful EVAR of their aneurysm is unlikely to alter their overall prognosis and life expectancy, which remains guarded (EVAR2 2005).

\section{Why it is important to do this review}

Ruptured abdominal aortic aneurysm is a catastrophic event that is occurring with increasing frequency as our population ages. Despite improved surgical techniques and advances in intensive care support, RAAA mortality was static for many years (Adam 1999; Huber 1995). However, in recent years it has improved, with large-volume centres associated with the improvement (Karthikesalingam 2014). The high mortality associated with open repair has led many to look for alternative treatments for the management of RAAA. Several studies have confirmed that the use of EVAR, especially under local anaesthesia, reduces the physiological insult to the body as compared to conventional open surgical repair (Cuypers 2001; Peppelenbosch 2003). The EVAR technique has been successfully used in the planned treatment of non-ruptured aneurysms of the abdominal aorta and, when compared to conventional open surgical repair, has been shown to reduce early postoperative complications and death. Emergency endovascular aneurysm repair (eEVAR) has been successfully carried out using a variety of protocols and techniques and would appear to offer a feasible alternative to conventional open repair in select patients (Peppelenbosch 2003; van Sambeek 2002). In this review we have assessed the available evidence to support the use of eEVAR to treat RAAA.

\section{OB JECTIVES}

To assess the advantages and disadvantages of emergency endovascular aneurysm repair (eEVAR) in comparison with conventional open surgical repair for the treatment of ruptured abdominal aortic aneurysm (RAAA). This will be determined by comparing the effects of eEVAR and conventional open surgical repair on short-term mortality, major complication rates, aneurysm exclusion (specifically endoleaks in the eEVAR treatment group), and late complications.

\section{METHODS}

\section{Criteria for considering studies for this review}

\section{Types of studies}

Prospective randomised controlled trials comparing eEVAR with emergency conventional open surgical repair.

\section{Types of participants}

All people in whom an RAAA has been clinically diagnosed by computed tomography (CT), angiography, magnetic resonance angiography (MRA), or objective acute symptoms suggestive of rupture of the aneurysm to warrant inclusion.

\section{Types of interventions}

We considered all types of endovascular devices in comparison with conventional open surgical treatment for patients considered fit for surgery.

\section{Types of outcome measures}

\section{Primary outcomes}

1. Short-term mortality (30-day or in-hospital mortality)

\section{Secondary outcomes}

1. Endoleak (blood within the vessel but outside the stent)

2. Major complications, e.g. open conversion, haemorrhage, myocardial infarction, stroke, renal failure, respiratory failure (need for postoperative mechanical ventilation), pneumonia, bowel ischaemia, lower limb ischaemia

3. Minor complications, e.g. catheter site haematoma, wound infection (associated with local wound or surgical site)

4. Complications and mortality at six months; we sought reintervention rates for problems related to the RAAA or its treatment as well as cause of death with or without reintervention, i.e. device-related

5. Complications and mortality long term (longer than six months); we sought re-intervention rates for problems related to the RAAA or its treatment as well as cause of death with or without reintervention, i.e. device-related

6. Quality of life (standardised questionnaires)

7. Economic analysis (cost per patient)

\section{Search methods for identification of studies}

\section{Electronic searches}

For this update the Cochrane Vascular Information Specialist (CIS) searched the following databases for relevant trials:

- Cochrane Vascular Specialised Register (22 June 2016);

- Cochrane Central Register of Controlled Trials (CENTRAL (2016, Issue 5)) via the Cochrane Register of Studies Online.

See Appendix 1 for details of the search strategy used to search CENTRAL.

The Cochrane Vascular Specialised Register is maintained by the $\mathrm{CIS}$ and is constructed from weekly electronic searches of MEDLINE Ovid, Embase Ovid, CINAHL, AMED, and through handsearching relevant journals. The full list of databases, journals, and conference proceedings that have been searched, as well as the search strategies used are described in the Specialised Register section of the Cochrane Vascular module in the Cochrane Library (www.cochranelibrary.com).

The CIS searched the following trial databases (22 June 2016) for details of ongoing and unpublished studies:

- World Health Organization International Clinical Trials Registry (WHO ICTRP) (apps.who.int/trialsearch/);

- ClinicalTrials.gov (clinicaltrials.gov/);

- ISRCTN Register (www.isrctn.com/). 
See Appendix 2 for details of the searches.

\section{Searching other resources}

We reviewed references of relevant studies for other pertinent publications.

\section{Data collection and analysis}

\section{Selection of studies}

Two review authors (SB and RF) independently reviewed the studies identified by the search for their relevance using the selection criteria. Disagreements were resolved through discussion.

MD and DWH performed study selection and evaluation of reporting bias in the previous version of this review.

\section{Data extraction and management}

Two review authors (SB and RF) independently extracted the data for each included study. We recorded details about the trial design, characteristics of participants, diagnosis of RAAA, eEVAR, and open repair procedures. We collected data on the primary outcome short-term mortality (30-day or in-hospital) and the secondary outcomes endoleak (30-day), major and minor shortterm complications, long-term mortality and complications (six months and one year), quality of life, and economic analysis.

\section{Assessment of risk of bias in included studies}

Two review authors (SB and RF) independently evaluated the included studies for quality using the Cochrane tool for assessing risk of bias (Higgins 2011). This tool is used to make judgements on the domains of sequence generation, allocation concealment, blinding, incomplete outcome data, selective outcome reporting, and other relevant biases. We judged each domain for each included study as low, unclear, or high risk. Any disagreements between review authors were resolved through discussion.

\section{Measures of treatment effect}

We planned analysis on an intention-to-treat basis, and therefore for all randomised participants from the included studies to be included in the analysis. We planned to compile the outcomes that were dichotomous in nature into a meta-analysis and to calculate odds ratios (ORs) with $95 \%$ confidence intervals (Cls). This excludes endoleak, which occurs only in the eEVAR treatment and is therefore inappropriate to compare in a meta-analysis; we planned to describe this through narrative synthesis. For continuous data, meta-analysis would provide mean differences with $95 \% \mathrm{Cls}$.

\section{Unit of analysis issues}

The individual participant was the unit of analysis.

\section{Dealing with missing data}

If data were missing from publications of the included studies, we attempted to contact the study authors.

\section{Assessment of heterogeneity}

A test for heterogeneity examines the null hypothesis that all studies are evaluating the same effect. We obtained $P$ values comparing the test statistic with a $\mathrm{Chi}^{2}$ distribution. To help readers assess the consistency of results of studies in a meta-analysis,
Review Manager 5 software includes a method ( ${ }^{2}$ statistic) that describes the percentage of total variation across studies due to heterogeneity rather than by chance (RevMan 2014). A value of $0 \%$ indicates no observed heterogeneity; larger values show increasing heterogeneity (Higgins 2003).

\section{Assessment of reporting biases}

To assess reporting bias, we planned to create funnel plots for meta-analyses containing 10 or more included studies. As only four studies were included in this review, no assessment of reporting bias could be undertaken.

\section{Data synthesis}

Data extracted independently by two review authors (SB and RF) were compiled and entered into Review Manager 5 by one review author (RF) (RevMan 2014). We undertook comparisons of data using meta-analyses employing fixed-effect models unless the $1^{2}$ value for heterogeneity yielded a value greater than $50 \%$, in which case we used a random-effects model.

\section{Subgroup analysis and investigation of heterogeneity}

We planned to perform subgroup analysis to evaluate the impact of participants treated with aorto-uni-iliac devices and those treated with aorto-bi-iliac devices. Two trials used only aorto-uni-iliac devices (AJAX; Hinchliffe 2006), while the other two used both methods, but the outcomes were not stratified by device used (ECAR; IMPROVE). Therefore, subgroup analysis was not possible due to the paucity of information. Also, due to the lack of outcome data stratified by other subgroups of interest, such as age and timing of the intervention, further subgroup analyses were not possible.

\section{Sensitivity analysis}

Although all the participants in the IMPROVE trial had a radiological diagnoses of RAAA, upon commencement of the intervention it was found that only $536(87 \%)$ of the 613 randomised participants in fact had a RAAA. The remaining 77 participants were diagnosed as follows: 10 participants had no AAA; 45 had asymptomatic AAA or other final diagnoses; and 22 had symptomatic non-ruptured AAA. We planned to perform sensitivity analysis to evaluate the effects of this trial on the outcomes.

\section{Summary of findings}

We constructed a 'Summary of findings' table for the comparison 'eEVAR versus open repair' using the GRADEpro GDT software to present the main findings of the review (GRADEpro GDT 2015). We judged the outcomes mortality (30-day or in-hospital), endoleaks, complications that included myocardial infarction, renal complications, respiratory failure, and bowel ischaemia, as well as mortality at six months to be the most clinically relevant to healthcare professionals and patients. We calculated assumed control intervention risks from the mean number of events in the control groups of the selected studies for each outcome. We used the system developed by the GRADE Working Group to grade the quality of the evidence as high, moderate, low, or very low, based on within-study risk of bias, directness of evidence, heterogeneity, precision of effects estimates, and risk of publication bias (Atkins 2004). We used Ryan 2016 's document on preparing 'Summary of findings' tables for reference. 


\section{RESULTS}

\section{Description of studies}

\section{Results of the search}

See Figure 1.

Figure 1. Study flow diagram.

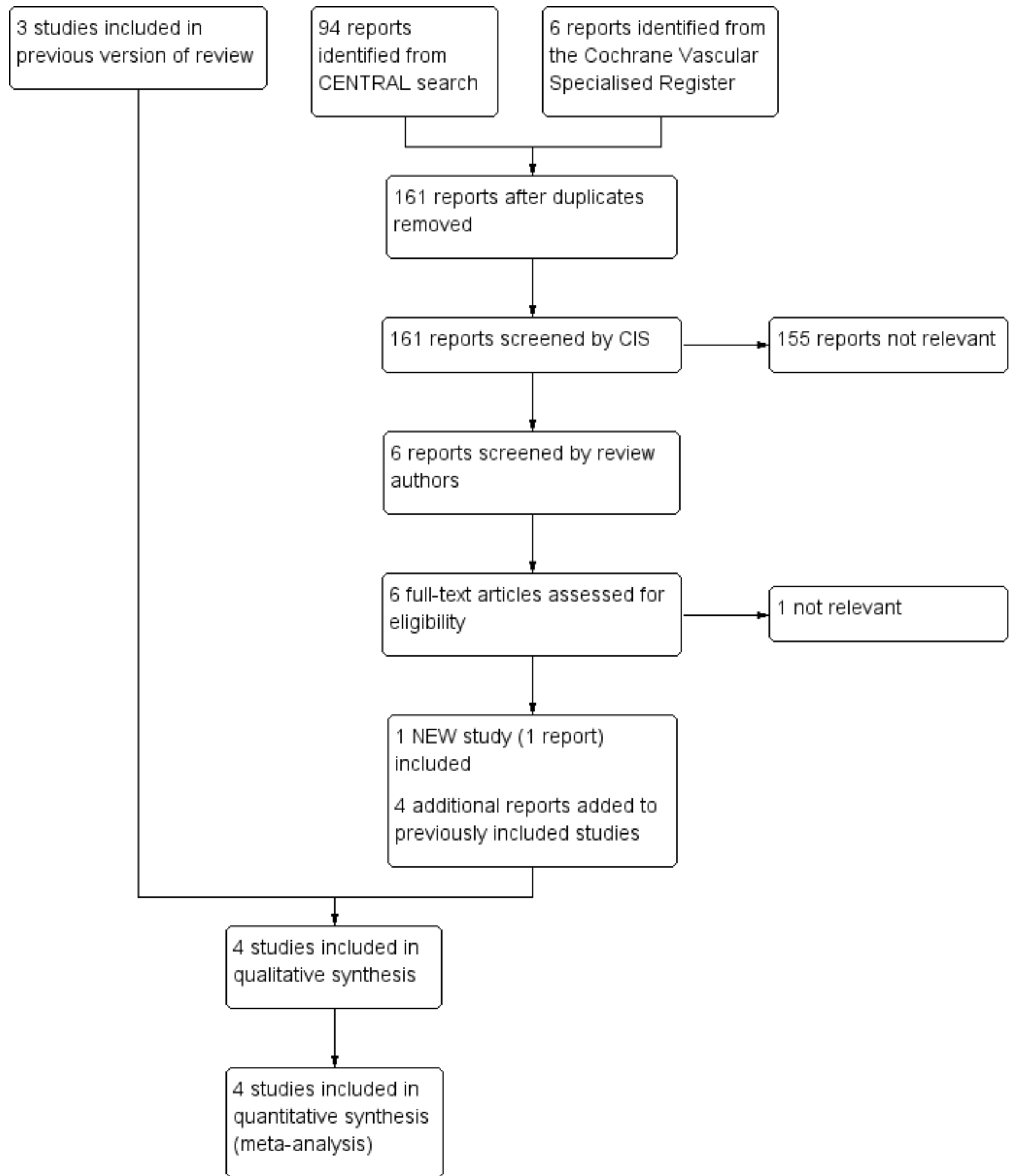




\section{Included studies}

See Characteristics of included studies for complete information on the included studies.

For this update we added an additional study that we had previously listed as 'ongoing' (ECAR). We have now included a total of four studies involving 868 participants (AJAX; ECAR; Hinchliffe 2006; IMPROVE). All four studies were randomised controlled trials comparing eEVAR to emergency open surgical repair in people with a clinical or radiological diagnosis of RAAA on outcomes that included mortality and complications. AJAX, ECAR, and IMPROVE aimed to evaluate longer-term mortality and complications, that is at six months and one year. The same three trials also evaluated cost-effectiveness by comparing cost per participant between the two trial arms. The IMPROVE trial was the only study to report on quality of life outcomes. None of the included studies directly evaluated minor complications.

AJAX, ECAR, and IMPROVE were all multicentre studies; AJAX took place in Amsterdam, the Netherlands, ECAR in France, and IMPROVE in the UK, with one study site in Canada. Hinchliffe 2006 was a single-centre trial taking place in England. All included participants had a clinical or radiological diagnosis of RAAA, but in the IMPROVE study only 536 out of the 613 (87\%) randomised participants actually had RAAA, with the remaining 77 participants diagnosed as follows: 10 participants had no AAA; 45 had asymptomatic AAA or other final diagnoses; and 22 had symptomatic non-ruptured AAA. All randomised participants in the AJAX and ECAR studies were considered suitable for both eEVAR and open repair; in the Hinchliffe 2006 and IMPROVE studies suitability for eEVAR was determined after randomisation. The Hinchliffe 2006 and AJAX studies used aorto-uni-iliac grafts in the endovascular trial arm; the ECAR and IMPROVE trials used both aorto-uni-iliac grafts and aortobi-iliac grafts.

\section{Excluded studies}

See Characteristics of excluded studies for more information on the excluded studies.

There were no newly excluded studies for this update, so there remains a total of five excluded studies (Peppelenbosch 2003; Resch 2003; Rödel 2012; Verhoeven 2002; Visser 2006). Three studies were prospective trials treating patients presenting with RAAA with eEVAR (Peppelenbosch 2003; Resch 2003; Verhoeven 2002). However, their comparison to open repair was made through retrospective, 'historical' controls or with open-repair cohorts. One study was a prospective comparison between eEVAR and open repair in people with RAAA, but the study was non-randomised (Rödel 2012). A final study was a non-randomised study of 55 consecutive patients presenting with RAAA (Visser 2006). A portion of the participants in the study were collected retrospectively and a portion prospectively.

\section{Risk of bias in included studies}

See Figure 2 and Figure 3.

\section{Figure 2. Risk of bias graph: review authors' judgements about each risk of bias item presented as percentages} across all included studies.

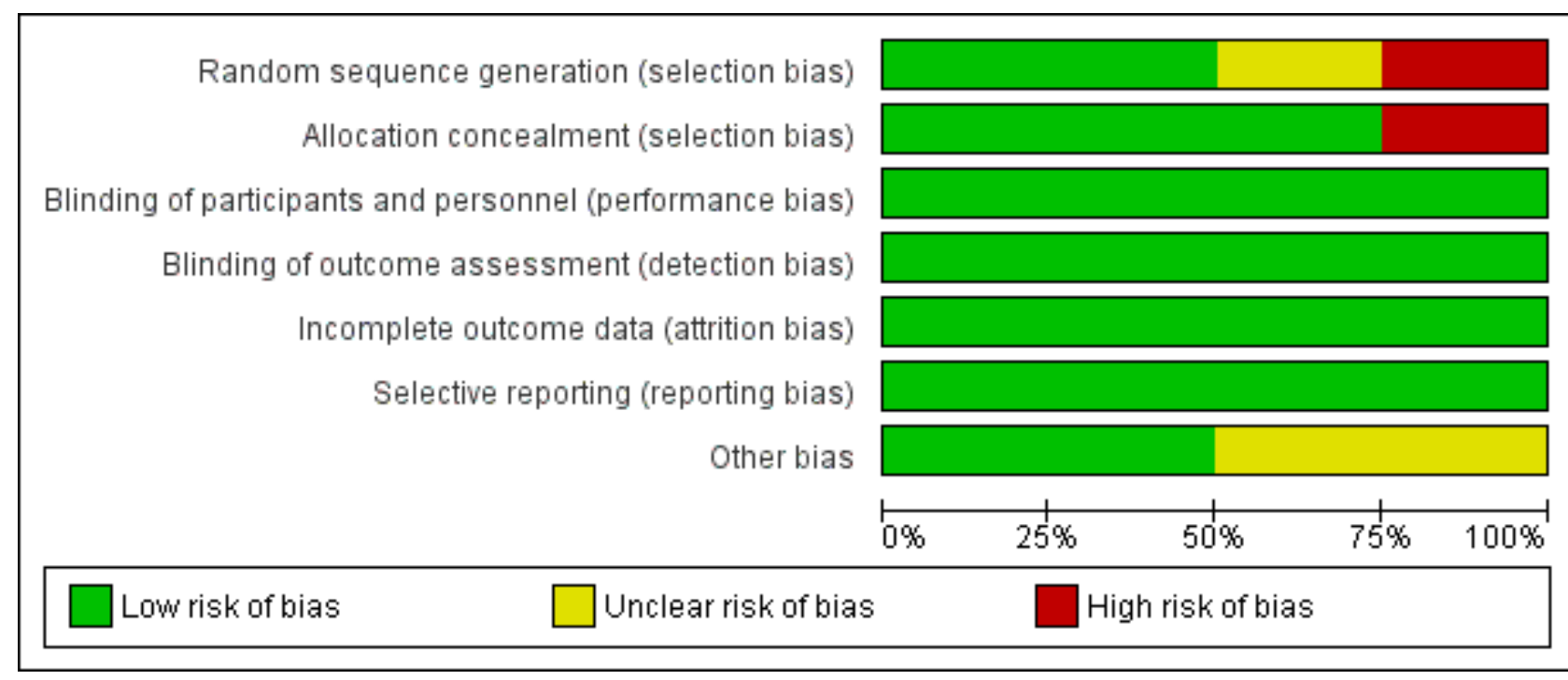


Figure 3. Risk of bias summary: review authors' judgements about each risk of bias item for each included study.

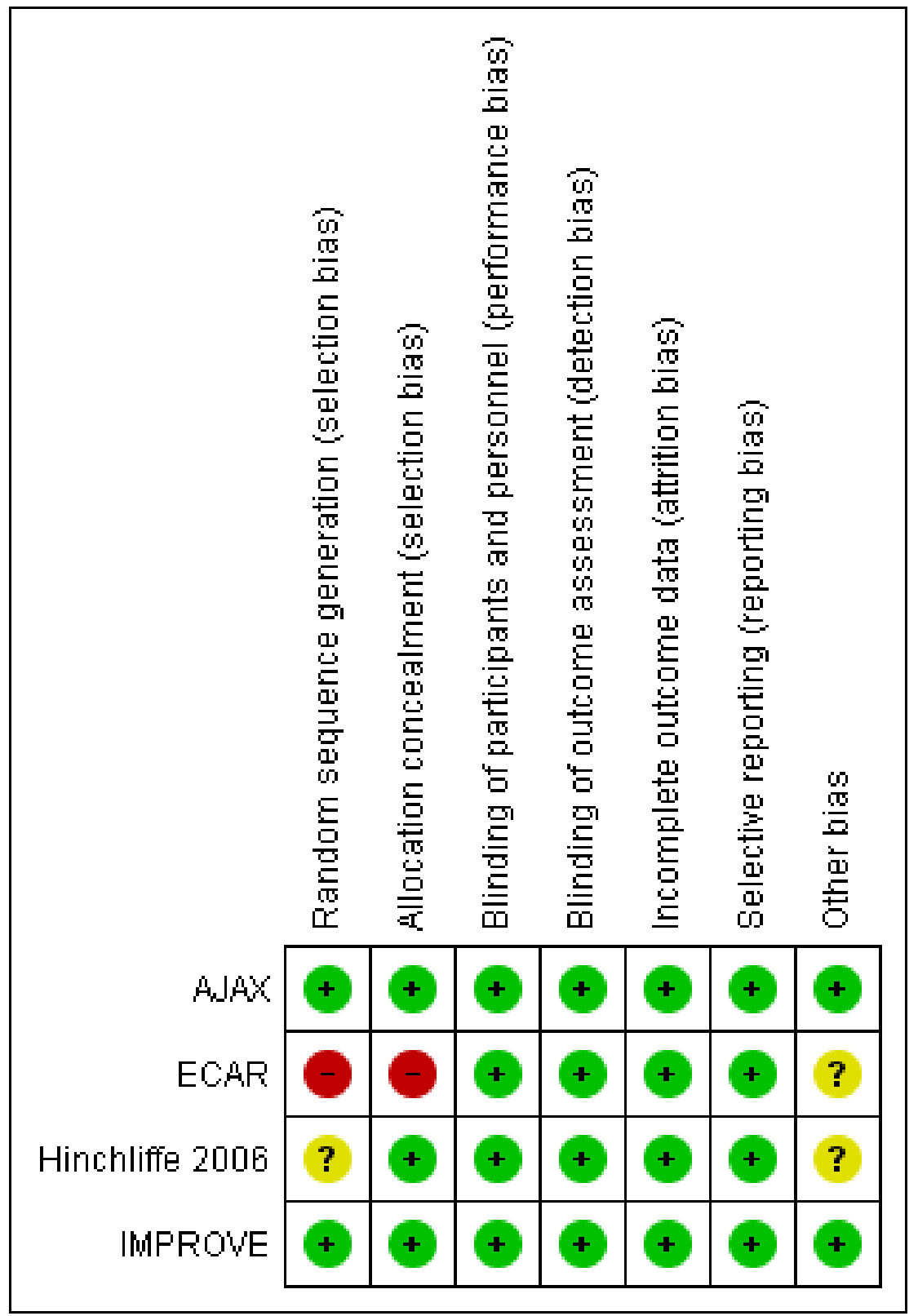

\section{Allocation}

We evaluated the ECAR study as being at high risk for selection bias, as they used a block randomisation technique by week with no allocation concealment. The authors provided their reasoning for this randomisation method, as it means they can prepare their surgical teams according to expertise: a team that is less proficient at a certain technique does not bias the results but performs the treatment less adequately than the other treatment. While this rationale does make sense, it still does not protect against selection bias, especially as the trial was unblinded. Both the AJAX and IMPROVE studies adequately reported random sequence generation, but the Hinchliffe 2006 study did not provide a description of how the allocation sequence was produced and was therefore considered to be at unclear risk of selection bias.
AJAX, Hinchliffe 2006, and IMPROVE all clearly explained adequate concealment methods.

\section{Blinding}

Due to the nature of the intervention, it was not possible to blind the surgeons, participants, and the research team to the treatment allocation, and this was not attempted in any of the included trials. However, we determined that a lack of blinding was unlikely to influence the outcomes of interest, and have assessed all four studies as being at low risk for performance and detection bias. Three of the studies attempted to reduce the risk of bias: in the AJAX study an endpoint adjudication committee and independent safety committee, both blinded to treatment allocation, were utilised; the Hinchliffe 2006 study kept surgeons blinded to dimensions of the aorta until randomisation was completed; and the IMPROVE study utilised a trial core laboratory to centrally verify outcomes. 


\section{Incomplete outcome data}

All four included studies adequately accounted for all participants, providing thorough explanations of dropout rates and the reasons for the dropouts. We judged all studies to be at low risk of attrition bias.

\section{Selective reporting}

All four included studies reported all specified outcomes, and so were all at low risk of reporting bias.

\section{Other potential sources of bias}

The AJAX and IMPROVE studies appeared to be free of other sources of bias, but the ECAR and Hinchliffe 2006 studies could have been at risk of bias due to an underpowered study population. ECAR calculated a need for 80 participants in each arm or a total of 160 participants to reach adequate power, but only randomised 107 participants. Hinchliffe 2006 reported that the study required 100 participants to be adequately powered, yet only included 32 participants.

\section{Effects of interventions}

See: Summary of findings for the main comparison Emergency endovascular aneurysm repair compared to conventional open repair for ruptured abdominal aortic aneurysm

See Summary of findings for the main comparison.

\section{Short-term mortality (30-day or in-hospital)}

We included all four studies in the meta-analysis for mortality (30-day or in-hospital) (AJAX; ECAR; Hinchliffe 2006; IMPROVE). For intention-to-treat purposes, we included all deaths that occurred after randomisation, which may have included deaths before intervention and perioperative deaths. Using the fixed-effect model, we found no clear evidence to support a difference in mortality between eEVAR and open repair (odds ratio (OR) 0.88 , $95 \%$ confidence interval $(\mathrm{Cl}) 0.66$ to $1.16 ; \mathrm{P}=0.36$; moderate-quality evidence) (Analysis 1.1). When we removed the IMPROVE study for sensitivity analysis, as in this study after commencement of treatment some randomised participants were found not to have RAAA, there was very little change in $\mathrm{OR}$, but the $\mathrm{Cl}$ became wider as the IMPROVE study had a larger study population than the other included studies (OR $0.78,95 \% \mathrm{Cl} 0.45$ to $1.33 ; \mathrm{P}=0.35$ ).

\section{Endoleak}

AJAX reported 33 endoleaks in the eEVAR treatment arm, that is 24 during the initial eEVAR procedure and nine during follow-up. Nine of the 33 endoleaks were type I and 10 were type II; the remaining 14 were not specified. The ECAR trial reported nine type II endoleaks diagnosed by computed tomography (CT) scan postoperatively. Hinchliffe 2006 reported two type I endoleaks, which were converted to open repair. The evidence for this outcome was of low quality.

\section{Major complications (30-day)}

\section{Combined major complications (as reported by studies)}

Three studies reported on combined major complications, but only two could be included in the meta-analysis. Data from AJAX and ECAR included in this analysis found no evidence of a difference in major complications between the treatment groups
(OR $0.72,95 \% \mathrm{Cl} 0.42$ to $1.23 ; \mathrm{P}=0.23$ ) (Analysis 1.2). We could not include the Hinchliffe 2006 study in the meta-analysis, as only percentages were supplied. Hinchliffe 2006 reported that $77 \%$ of participants in the eEVAR group experienced moderate or severe complications, and $80 \%$ in the open-repair group experienced such events. It should be noted the studies included in the analysis had different definitions and included different types of events as major complications.

\section{Myocardial infarction}

ECAR and Hinchliffe 2006 reported myocardial infarction; only four events were reported, so the $\mathrm{Cl}$ was very wide $(\mathrm{OR} 2.38,95 \% \mathrm{Cl} 0.34$ to $16.53 ; \mathrm{P}=0.38$; low-quality evidence) (Analysis 1.3).

\section{Stroke}

Both the AJAX and Hinchliffe 2006 studies reported stroke events but with very few events, and opposing findings. Using the fixedeffect model, we found the non-significant OR had a very wide $\mathrm{Cl}$, from which it was difficult to derive any meaningful conclusion (OR $0.71,95 \% \mathrm{Cl} 0.12$ to $4.31 ; \mathrm{P}=0.71$ ) (Analysis 1.4 ).

\section{Cardiac complications (moderate or severe)}

The AJAX, ECAR, and Hinchliffe 2006 studies evaluated cardiac complications. The fixed-effect meta-analysis found a no difference between the treatment groups $(\mathrm{OR} 0.84,95 \% \mathrm{Cl} 0.32$ to 2.23 ; $\mathrm{P}=$ 0.73) (Analysis 1.5).

\section{Renal complications (moderate or severe)}

The AJAX, ECAR, and Hinchliffe 2006 studies reported renal complications. Using the random-effects model, we found no clear difference between the interventions (OR 1.07, 95\% Cl 0.21 to 5.42; $\mathrm{P}=0.93 ; \mathrm{I}^{2}=77 \%$; low-quality evidence) (Analysis 1.6).

\section{Respiratory failure}

Only the Hinchliffe 2006 study evaluated respiratory failure. With only a single event in the eEVAR arm, the $\mathrm{Cl}$ was very wide (OR $3.62,95 \% \mathrm{Cl} 0.14$ to 95.78 ; low-quality evidence), with no overall association (Analysis 1.7).

\section{Bowel ischaemia}

AJAX and ECAR evaluated bowel ischaemia, and found a reduction in the odds of bowel ischaemia in the eEVAR treatment group, with an OR of 0.37 ( $95 \% \mathrm{Cl} 0.14$ to $0.94 ; \mathrm{P}=0.04$; low-quality evidence) (Analysis 1.8).

\section{Spinal cord ischaemia}

Only the AJAX study evaluated spinal cord ischaemia, with only one event. With an OR of 3.16 and a very wide $\mathrm{Cl}(95 \% \mathrm{Cl} 0.13$ to 79.17$)$, we could conclude very little regarding this outcome (Analysis 1.9).

\section{Reoperation}

AJAX and Hinchliffe 2006 reported the occurrence of reoperation specific to the aneurysm repair. Using the fixed-effect model, we found no clear evidence to support a difference between the interventions ( $\mathrm{OR} 0.89,95 \% \mathrm{Cl} 0.39$ to $2.01 ; \mathrm{P}=0.78$ ) (Analysis 1.10). 


\section{Amputation}

AJAX and ECAR evaluated amputation. There were only five total events, all in the open repair intervention group (OR $0.16,95 \% \mathrm{Cl}$ 0.02 to $1.32 ; \mathrm{P}=0.09$ ) (Analysis 1.11).

\section{Open conversion}

As open conversion could only be evaluated in the eEVAR treatment group, meta-analysis was not an appropriate way to compare this outcome among the three studies in which it was reported. The AJAX trial reported 10 cases of open conversion in the 57 (17.5\%) participants randomised to eEVAR. Hinchliffe 2006 had one open conversion out of the 15 (6.7\%) participants randomised to eEVAR, and the IMPROVE study reported four out of the $316(1.3 \%)$ randomised participants, which was far lower than the other two trials. This could be due to the $13 \%$ of randomised participants in the IMPROVE study who were found not to have RAAA (10 participants had no AAA; 45 had asymptomatic AAA or other final diagnoses; and 22 had symptomatic non-ruptured AAA); also, 84 participants randomised to eEVAR were determined unsuitable for the procedure and moved to open repair but were not considered as open-conversion participants.

\section{Minor complications}

None of the included studies directly evaluated minor complications.

\section{Mortality and complications at six months or longer}

In the AJAX trial there was no clear evidence to support a difference between the interventions for mortality (OR $0.89,95 \% \mathrm{Cl} 0.40$ to 1.98); combined major complications (OR $0.84,95 \% \mathrm{Cl} 0.39$ to 1.80 ); or reoperation (OR 1.28, $95 \% \mathrm{Cl} 0.53$ to 3.06 ) (Analysis 1.12; Analysis 1.13; Analysis 1.14) at six months.

The IMPROVE trial reported mortality at one year (OR $0.85,95 \% \mathrm{CI}$ 0.62 to 1.17 ) (Analysis 1.15). We could draw no conclusions from the single study.

ECAR evaluated mortality at six months and one year, finding no differences between the treatment groups; however, they have not reported the values needed to include the data in our metaanalysis. We have contacted the authors to obtain the necessary data.

\section{Quality of life}

The AJAX study included quality of life data from two questionnaires, the 36-Item Short Form Health Survey (SF-36) and the EuroQol Group, Rotterdam, the Netherlands (EQ-5D). At six months there was no difference in the either the physical component or mental component of the SF-36: eEVAR 44.33 and 44.68 , and open repair 40.77 and 49.93 , respectively. There were also no differences between treatment groups for the EQ-5D: eEVAR 32 and open repair 31.

Table 1 contains peri- and postoperative participant characteristics that we did not consider as outcomes in this review but are of interest when comparing eEVAR with open repair, and also for comparisons between the trials. The table addresses time spent waiting for surgical intervention; time in the operating theatre; blood loss during the operation; and length of time spent in the hospital. As two studies used median and interquartile range, one study used mean and range and one study used mean and standard deviation, we could not compare the findings quantitatively but used them for anecdotal analysis.

\section{Economic analysis (cost per patient)}

AJAX, ECAR, and IMPROVE evaluated the cost per patient, but only IMPROVE could be used for analysis, as the other two studies supplied insufficient data for comparison (we have contacted the authors but received no response). IMPROVE found the mean cost slightly less in the eEVAR-treated arm after 30 days: GBP 13,433 compared to GBP 14,619 in the open-repair group. We found the mean difference to be GBP 1186 favouring eEVAR, but as both trial arms had large standard deviations, the $95 \% \mathrm{Cl}$ was very wide, spanning GBP -2996.24 to GBP 624.24. As we could include only a single study in the cost analysis, we could determine no overall association (Analysis 1.16).

The AJAX trial reported the costs for eEVAR over 30 days postoperatively to be EUR 32,742, and EUR 27,436 for open repair. ECAR reported EUR 7087.5 for eEVAR and EUR 9329.4 for open repair for the cost of participants' hospital stay.

\section{DISCUSSION}

\section{Summary of main results}

We included four studies in this review with a total of 868 participants randomised to receive either eEVAR or open repair to treat an RAAA. All four studies reported on short-term mortality, defined as either 30-day or in-hospital; the meta-analysis found no significant difference between eEVAR and open repair. Only three studies reported 30-day complications (low-quality evidence), and many of the individual 30-day complication outcomes were only reported in a single study. We rated the evidence for myocardial infarction, renal complications, and respiratory failure as low quality. Bowel ischaemia was the only complication with a statistically significant association, favouring eEVAR (low-quality evidence). Three studies reported longer-term outcomes, mortality and complications at six months and one year, but we evaluated only two by meta-analysis (one at six months and one at one year). We could not determine a conclusion regarding either of the long-term outcomes with such a paucity of data. We evaluated evidence for six-month mortality as of moderate quality. Only a single study evaluated quality of life, from which no conclusions could be drawn. Three studies reported cost per patient, but only a single study could be evaluated for analysis, with a slight decrease in cost for participants randomised to eEVAR.

At present we are unable to draw any significant conclusions regarding the superiority of either of the interventions for mortality and complication outcomes. Hopefully with further high-quality studies being undertaken evaluating eEVAR versus open repair for RAAA we will better understand if there is truly no difference between these two interventions regarding the outcomes evaluated in this review, or if we simply do not have enough data at this time to determine any differences.

\section{Overall completeness and applicability of evidence}

The four studies included in this review were of good quality, with the exception of an assessment of high risk of selection bias for a single study. The evidence gathered using the four studies can be considered relevant, however insufficient data make any conclusions spurious at this time. There was little information to 
support an association for the outcomes addressed in this review, and our other outcomes of interest, such as minor complications, were not acknowledged within the studies.

All four included studies required a clinical or radiological diagnosis of RAAA for inclusion in the study, yet the IMPROVE study, upon commencement of intervention, found that $13 \%$ of their included randomised participants did not have RAAA: 10 participants had no AAA; 45 had asymptomatic AAA or other final diagnoses; and 22 had symptomatic non-ruptured AAA; the study authors claimed this was a more "real world" approach to the issue. While this may not affect the overall outcomes, it is of concern and should be kept in mind. Also, the IMPROVE trial did not assess eEVAR suitability prior to randomisation, which resulted in 84 participants randomised to eEVAR not being suitable for the procedure and transferred to open repair. Hinchliffe 2006 also did not select participants for their suitability for both eEVAR and open repair prior to randomisation, and one participant randomised to EEVAR was transferred to open repair. The AJAX and ECAR trials evaluated a more select population of participants suitable for both eEVAR and open repair. Consequently, there are two separate questions being addressed in the trials, namely if an EVAR strategy for all RAAAs would work (IMPROVE), or if EVAR-suitable patients are better treated thus or by open surgery (AJAX; ECAR). Such issues are emphasised by the IMPROVE trial's findings that aortic morphology, specifically neck length, has an effect on patient outcome. For our review analysis we found a paucity of subgroup data, which meant that we were unable to carry out any of the planned subgroup analyses, and it was therefore not possible to assess in detail whether certain patient groups may benefit more from EVAR or open surgery. With future updates of this review we hope more detailed subgroup data will be made available so we can provide a more robust analysis.

\section{Quality of the evidence}

In the update of this review 868 participants from four trials of good quality have been included for analysis. Risk of bias of the included studies was generally low, but one study used a block randomisation technique by week with no allocation concealment and was unblinded, leading to a high risk of selection bias (ECAR). Another study did not adequately report random sequence generation (Hinchliffe 2006), putting it at risk of selection bias. The same two studies were underpowered as per their own calculations reported by the study authors (ECAR; Hinchliffe 2006), leading to an unclear risk of other bias. The data from these four studies are insufficient for us to be able to draw any robust conclusions about the outcomes evaluated in this review regarding the comparison of eEVAR and open repair for the treatment of RAAA.

The quality of the evidence according to GRADE varied by outcome and was assessed as moderate to low. Several outcomes had issues with heterogeneity, leading to inconsistency, and most outcomes included few participants or events, leading to imprecision. We were unable to evaluate the outcome of endoleaks using metaanalysis as it occurs only in the eEVAR treatment group, but we found significant heterogeneity in the reported events in each of the three reporting trials. This outcome remains an important factor for success for eEVAR and should be evaluated in future trials. For the outcomes that had a majority of participants from the ECAR study, we downgraded for risk of bias as the study did not have adequate random sequence generation and allocation concealment techniques. See Summary of findings for the main comparison.
The outcomes from the Hinchliffe 2006 study used in our review were gathered from descriptions within the text of the publication and were not presented in a table. We contacted the authors to confirm these outcomes, but received no response. In addition, in the Hinchliffe 2006 study the single myocardial infarction, stroke, and respiratory failure events were all from the same individual.

\section{Potential biases in the review process}

Two review authors independently performed study selection, data extraction, and quality assessment in order to reduce bias and subjectivity. We are confident that all potential sources of data to be included in this review were carefully vetted. However, the possibility remains that there exist relevant data that we did not include in this review, which were not published or were not found in the search.

\section{Agreements and disagreements with other studies or reviews}

To our knowledge this is the first systematic review evaluating only studies that are prospective randomised controlled trials (RCTs) comparing eEVAR with open repair in people with RAAA. Other studies, including several systematic reviews, have addressed eEVAR versus open repair in people with RAAA, but these have been mostly observational, non-randomised studies, many of which were retrospective. These types of studies are more likely to be subject to bias compared with RCTs.

A systematic review from 2007 included 10 studies, all of which were observational studies, using as their inclusion criteria that there was a comparison between people who underwent eEVAR and people who underwent open surgery; a minimum of five participants in each treatment group; data available on patients' haemodynamic condition at presentation; and availability of 30day mortality data (Visser 2007). The Visser 2007 review did not include any of the studies included in our systematic review. A crude random-effects model for 30-day mortality, comparing eEVAR with open repair, found an OR of 0.45 ( $95 \% \mathrm{Cl} 0.28$ to 0.72 ), and when the patient haemodynamic condition at presentation, which varied between studies, was included in the model, the adjusted $\mathrm{OR}$ was $0.67(95 \% \mathrm{Cl} 0.31$ to $1.44 ; \mathrm{P}=0.37)$. These results indicate that both eEVAR and open repair are suitable for treatment of people with RAAA, and that eEVAR may have a higher 30-day survival. The crude and adjusted ORs showed a stronger relationship between eEVAR and lower mortality than did our results for the 30-day mortality outcome, which showed no difference between the two interventions. The Visser 2007 review also evaluated a composite systemic complications outcome, which found a lower point estimate within the eEVAR group (28\%, $95 \% \mathrm{Cl} 17 \%$ to $48 \%$ ) compared with open repair (56\%, 95\% Cl 37\% to $85 \%$ ), indicating fewer complications within the eEVAR group. We did not have sufficient data on complications in our review to compare with these results, and we did not include a composite systemic complications outcome.

The Takagi 2011 meta-analysis included 11 RCTs or risk-adjusted observational studies with a total of 42,888 participants. The inclusion criteria for this review required studies to be RCTs or riskadjusted observational comparative studies with acceptable riskadjustment methods (propensity score analyses or multivariate logistic regression); the study population be people with RAAA; participants were assigned to eEVAR or open repair; and outcomes 
include in-hospital or 30-day mortality. This review included one RCT, which we also included in our review, and 10 observational studies. The random-effects model found a statistically significantly OR of 0.49 (95\% Cl 0.35 to $0.69 ; \mathrm{P}<0.001)$. While our mortality results showed little difference in mortality between eEVAR and open repair, the Takagi 2011 study showed a strong relationship between eEVAR and lower mortality.

The findings of another meta-analysis also reflect these results (Qin 2014). Qin 2014 included a total of 18 studies, of which 12 were retrospective, four were prospective but with observational or retrospective components, and two were RCTs, which were also included in our review. This review demonstrated a lower mortality (OR $0.62,95 \% \mathrm{Cl} 0.58$ to $0.67 ; \mathrm{P}<0.001$ ) and shorter length of stay in the eEVAR group (mean difference -5.25 days, $95 \% \mathrm{Cl}-9.23$ to -1.26 ; $P=0.010$ ), which differed from our own conclusion of no difference between the two interventions. However, the heterogeneity of study designs in the meta-analysis significantly detracts from the quality of the results and conclusions.

A meta-analysis performed by van Beek 2014 also attempted to evaluate the effects of eEVAR versus open surgery for RAAA on 30day or in-hospital mortality. This review included RCTs as well as observational studies and administrative registries. The three RCTs included by van Beek 2014 were the same as those included in this Cochrane review, therefore their OR was nearly identical to ours for 30-day or in-hospital mortality (OR $0.90,95 \% \mathrm{Cl} 0.65$ to 1.24 ; $\mathrm{P}=0.966)$. The 21 observational studies and eight administrative registries included by van Beek 2014 showed reduced mortality in the eEVAR group, which reflects the meta-analyses described above that also included observational studies.

A recent literature review and meta-analysis included 41 studies, of which two were RCTs and the remaining studies were observational, population-based studies, with a total of 59,941 participants (Antoniou 2013). The two RCTs were also included in our review. Antoniou 2013 included studies if they compared perioperative outcomes of eEVAR and open repair of ruptured infrarenal or juxtarenal AAA, and included all types of comparative studies. Using a random-effects model, the review authors found a statistically significant lower mortality for participants who underwent eEVAR compared with open repair (OR $0.56,95 \% \mathrm{Cl}$ 0.50 to $0.64 ; \mathrm{P}<0.001$ ). The mortality outcome of the Antoniou 2013 review shows a strong mortality odds reduction for the eEVAR group, whereas our review found little difference between the eEVAR and open-repair groups. The Antoniou 2013 study also showed a lower risk for many of the complications evaluated in those who underwent eEVAR, such as respiratory complications (OR $0.59,95 \% \mathrm{Cl} 0.49$ to $0.69 ; \mathrm{P}<0.001$ ) and acute renal failure (OR $0.65,95 \% \mathrm{Cl} 0.55$ to $0.78 ; \mathrm{P}<0.001$ ), as well as trends towards lower risk in the eEVAR group, however statistically insignificant, of lower limb ischaemia (OR $0.63,95 \% \mathrm{Cl} 0.37$ to $1.07 ; \mathrm{P}=$ 0.09 ) and mesenteric ischaemia (OR $0.66,95 \% \mathrm{Cl} 0.44$ to 1.00 ; $P=0.05)$. The authors also evaluated cardiac complications, but mistakenly measured risk difference (RD) instead of OR and showed a borderline statistically significant RD favouring eEVAR (RD -0.02, $95 \% \mathrm{Cl}-0.03$ to $0.00 ; \mathrm{P}=0.05$ ). We were unable to compare the findings for the complications outcomes in our review as data were insufficient for us to be able to make any definitive conclusions. after receiving either eEVAR or open repair for RAAA (Sweeting 2015; Sweeting 2015a). The three studies included in this meta-analysis were also included in our review (AJAX; ECAR; IMPROVE). Sweeting 2015 calculated very similar results to our own, with no difference in mortality at 30 days (OR $0.88,95 \% \mathrm{Cl} 0.66$ to 1.18 ), also finding no difference at 90 days (OR $0.85,95 \% \mathrm{Cl} 0.64$ to 1.13 ). There was still no difference in mortality between the treatment groups at one year (OR $0.84,95 \% \mathrm{Cl} 0.63$ to 1.11 ) (Sweeting 2015a), which was similar to our own findings, but we were only able to include the data from a single study (IMPROVE).

\section{AUTHORS' CONCLUSIONS}

\section{Implications for practice}

The conclusions of this review are currently limited by the paucity of data. From the data available we found moderate-quality evidence of no difference between eEVAR and open repair for the primary outcome evaluated in this review, 30-day or in-hospital mortality. Not enough information was provided for complications for us to be able to make well-informed conclusions at this time, although there was some evidence of reduced bowel ischaemia in the emergency endovascular aneurysm repair (eEVAR) treatment group. Longterm data are lacking for both survival and late complications.

\section{Implications for research}

Further trials are required to evaluate the role of eEVAR in the treatment of ruptured abdominal aortic aneurysm. These trials should be methodologically adequate in terms of sample sizes, treatment standardisation, and duration of follow-up. Clinically relevant outcomes such as rate of major complications, open conversion, aneurysm exclusion, endoleak, rupture, and mortality should be addressed. Long-term results on survival and secondary interventions will also be an important aspect of future results. However, accumulating evidence from non-randomised studies, which shows significant reductions in mortality in select patients deemed suitable for endovascular repair, may raise ethical concerns with regard to randomising these patients to open repair. Large prospective studies are required to validate the acceptable anatomical criteria for eEVAR in ruptured abdominal aortic aneurysm. Furthermore, longitudinal studies are required to assess the long-term durability of this form of treatment in terms of re-intervention rate, open-conversion rate, and rupture-free survival. There are indications that eEVAR patients have a higher rate of discharge to home with associated enhanced quality of life, and also that aortic morphology could be important for outcomes. Due to a paucity of data for our review we were unable to undertake any subgroup analysis that could illuminate if certain patient groups may benefit more from one or the other intervention. This is of vital interest to patients and deserves more attention in future research. Finally, as EVAR device technology improves, outcome differences may emerge in future research.

\section{ACK N OWLEDGEMENTS}

We would like to thank the members of the Cochrane Vascular editorial board for their guidance and support, and Marianne Dillon and Chris Cardwell for their work on the previous version of this review.

A recent individual patient data meta-analysis was conducted from three RCTs evaluating mortality at 30 days, 90 days, and one year 


\section{R E F E R E N C E S}

\section{References to studies included in this review}

AJAX \{published data only\}

Balm R. AJAX confirms no difference between EVAR and open repair for ruptured aneurysms. www.cxvascular.com/cx-latestnews/cx-latest-news/ajax-confirms-no-difference-betweenevar-and-open-repair-for-ruptured-aneurysms (accessed 21 April 2014).

Hoornweg LL, Balm R, Legemate DA, Idu MM, Kox C, Reekers JA, et al. Amsterdam Acute Aneurysm Trial: Background, design, and methods. Vascular 2006;14(3):130-5.

Hoornweg LL, Wisselink W, Vahl A, Balm R, Amsterdam Acute Aneurysm Trial Collaborators. The Amsterdam Acute Aneurysm Trial: suitability and application rate for endovascular repair of ruptured abdominal aortic aneurysms. European Journal of Vascular and Endovascular Surgery 2007;33(6):679-83.

ISRCTN66212637. Acute endovascular treatment to improve outcome of ruptured aorto-iliac aneurysms. The AJAX trial. www.isrctn.com/ISRCTN66212637 (first received 12 September 2005).

Kapma MR, Dijksman LM, Reimerink JJ, de Groof J, Zeebregts CJ, Wisselink W, et al. Cost-effectiveness and cost-utility of endovascular versus open repair of ruptured abdominal aortic aneurysm in the Amsterdam Acute Aneurysm Trial. British Journal of Surgery 2014;101(3):208-15.

* Reimerink JJ, Hoornweg LL, Vahl AC, Wisselink W, van den Broek TA, Legemate DA, et al. Endovascular repair versus open repair of ruptured abdominal aortic aneurysms: A multicenter randomized controlled trial. Annals of Surgery 2013;258(2):248-56.

\section{ECAR \{published data only\}}

Desgranges $\mathrm{P}$, Kobeiter $\mathrm{H}$, Castier $\mathrm{Y}$, Senechal M, Majewski M, Krimi A. The Endovasculaire vs Chirurgie dans les Anevrysmes Rompus PROTOCOL trial update. Journal of Vascular Surgery 2010;51(1):267-70.

* Desgranges P, Kobeiter H, Katsahian S, Bouffi M, Gouny P, Favre JP, et al. ECAR (Endovasculaire ou Chirurgie dans les Anevrysmes aorto-iliaques Rompus): A French randomized controlled trial of endovascular versus open surgical repair of ruptured aorto-iliac aneurysms. European Journal of Vascular and Endovascular Surgery 2015;50(3):303-10.

NCT00577616. Ruptured Aorta-iliac Aneurysms: Endo vs. Surgery (ECAR). clinicaltrials.gov/ct2/show/NCT00577616 (first received 19 December 2007).

\section{Hinchliffe 2006 \{published data only\}}

Hinchliffe RJ, Bruijstens L, MacSweeney STR, Braithwaite BD. A randomised trial of endovascular and open surgery for ruptured abdominal aortic aneurysm - results of a pilot study and lessons learned for future studies. European Journal of Vascular and Endovascular Surgery 2006;32(5):506-13.
IMPROVE \{published data only\}

Ambler GK, Twine CP, Shak J, Rollins KE, Varty K, Coughlin PA, et al. Survival following ruptured abdominal aortic aneurysm before and during the IMPROVE trial: A single-centre series. European Journal of Vascular and Endovascular Surgery 2014;47(4):388-93.

Braithwaite B, Greenhalgh RM, Grieve R, Hassan TB, Moore F, Nicholson AA, et al. Endovascular strategy or open repair for ruptured abdominal aortic aneurysm: One-year outcomes from the IMPROVE randomized trial. European Heart Journal 2015;36(31):2061-9.

IMPROVE Trial Investigators. Observations from the IMPROVE trial concerning the clinical care of patients with ruptured abdominal aortic aneurysm. British Journal of Surgery 2014;101:216-24.

IMPROVE Trial Investigators. The effect of aortic morphology on peri-operative mortality of ruptured abdominal aortic aneurysm. European Heart Journal 2015;36(21):1328-34.

* IMPROVE Trial Investigators, Powell JT, Sweeting MJ, Thompson MM, Ashleigh R, Bell R, et al. Endovascular or open repair strategy for ruptured abdominal aortic aneurysm: 30day outcomes from IMPROVE randomised trial. BMJ (Clinical research ed.) 2014;348:f7661.

IMPROVE Trial, Powell JT, Thompson SG, Thompson MM, Grieve R, Nicholson AA, et al. The immediate management of the patient with rupture: open versus endovascular repair (IMPROVE) aneurysm trial. Acta Chirurgica Belgica 2009;109(6):678-80. [ISRCTN 48334791]

NCT00746122. Immediate management of the patient with aneurysm rupture: open versus endovascular repair (IMPROVE). clinicaltrials.gov/ct2/show/NCT00746122 (first received 1 September 2008).

National Insitute for Health Research. IMPROVE: Can eEVAR reduce mortality from ruptured AAA? Protocol. National Health Institute for Health Research: Evaluation, Trials and Studies Coordinating Centre. www.nets.nihr.ac.uk/projects/hta/073764 (accessed 21 April 2014).

Powell JT. Aortic neck length and mortality after repair of ruptured abdominal aortic aneurysm. Circulation 2014; Vol. 130:A15047.

\section{References to studies excluded from this review}

Peppelenbosch 2003 \{published data only\}

Peppelenbosch N, Yilmaz N, van Marrewijk C, Buth J, Cuypers P, Duijm L, et al. Emergency treatment of acute symptomatic or ruptured abdominal aortic aneurysm. Outcome of a prospective intent-to-treat by EVAR protocol. European Journal of Vascular and Endovascular Surgery 2003;26(3):303-10. 
Resch 2003 \{published data only\}

Resch T, Malina M, Lindblad B, Dias NV, Sonesson B, Ivancev K. Endovascular repair of ruptured abdominal aortic aneurysms: logistics and short-term results. Journal of Endovascular Therapy 2003;10(3):440-6.

Rödel 2012 \{published data only\}

Rödel SG, Meerwaldt R, Beuk RJ, Huisman AB, Zeebregts CJ, Geelkerken RH, et al. Endovascular treatment of ruptured abdominal aortic aneurysm: is there a long-term benefit at follow-up?. Journal of Cardiovascular Surgery 2012;53(1):83-9.

\section{Verhoeven 2002 \{published data only\}}

Verhoeven EL, Prins TR, van den Dungen JJ, Tielliu IF, Hulsebos RG, van Schilfgaarde R. Endovascular repair of acute AAAs under local anaesthesia with bifurcated endografts: a feasibility study. Journal of Endovascular Therapy 2002;9(6):729-35.

\section{Visser 2006 \{published data only\}}

Visser JJ, Bosch JL, Hunink MG, Van Dijk LC, Hendriks JM, Poldermans, et al. Endovascular repair versus open surgery in patients with ruptured abdominal aortic aneurysms: clinical outcomes with 1-year follow-up [see comment]. Journal of Vascular Surgery 2006;44(6):1148-55.

\section{Additional references}

\section{Adam 1999}

Adam DJ, Mohan IV, Stuart WP, Bain M, Bradbury AW. Community and hospital outcome from ruptured abdominal aortic aneurysm within the catchment area of a regional vascular surgical service. Journal of Vascular Surgery 1999;30(5):922-8.

\section{Alsac 2005}

Alsac JM, Kobeiter H, Becquemin JP, Desgranges $\mathrm{P}$. Endovascular repair for ruptured AAA: a literature review. Acta Chirurgica Belgica 2005;105(2):134-9.

\section{Antoniou 2013}

Antoniou GA, Georgiadis GS, Antoniou SA, Pavlidis P, Maras D, Sfyroeras GS, et al. Endovascular repair for ruptured abdominal aortic aneurysm confers an early survival benefit over open repair [Review]. Journal of Vascular Surgery 2013;58(4):1091-105.

\section{Ashton 2002}

Ashton HA, Buxton MJ, Day NE, Kim LG, Marteau TM, Scott RA, et al. The Multicentre Aneurysm Screening Study (MASS) into the effect of abdominal aortic aneurysm screening on mortality in men: a randomised controlled trial. Lancet 2002;360(9345):1531-9.

\section{Atkins 2004}

Atkins D, Best D, Briss PA, Eccles M, Falck-Ytter Y, Flottorp S, et al. Grading quality of evidence and strength of recommendations. BMJ 2004;328(7454):1490-4.

\section{Brown 2012}

Brown LC, Powell JT, Thompson SG, Epstein DM, Sculpher MJ, Greenhalgh RM. The UK Endovascular Aneurysm Repair (EVAR) trials: randomised trials of EVAR versus standard therapy. Health Technology Assessment 2012;16(9):1-218.

\section{CAESAR Trial}

Cao P, De Rango P, Verzini F, Parlani G, Romano L, Cieri E, et al. Comparison of surveillance versus aortic endografting for small aneurysm repair (CAESAR): results from a randomised trial. European Journal of Vascular and Endovascular Surgery 2011;41(1):13-25.

\section{Conway 2012}

Conway AM, Malkawi AH, Hinchliffe RJ, Holt PJ, Murray S, Thompson MM, et al. First-year results of a national abdominal aortic aneurysm screening programme in a single centre. British Journal of Surgery 2012;99(1):73-7.

\section{Cosford 2007}

Cosford PA, Leng GC, Thomas J. Screening for abdominal aortic aneurysm. Cochrane Database of Systematic Reviews 2007, Issue 2. [DOI: 10.1002/14651858.CD002945.pub2]

\section{Cuypers 2001}

Cuypers PWM, Gardien M, Buth J, Peels CH, Charbon JA, Hop WC. Randomized study comparing cardiac response in endovascular and open aortic aneurysm repair. British Journal of Surgery 2001;88(8):1059-65.

\section{EVAR 2004}

Greenhalgh RM, Brown LC, Kwong GP, Powell JT, Thompson SG. EVAR trial participants. Comparison of endovascular aneurysm repair with open repair in patients with abdominal aortic aneurysm (EVAR trial 1), 30-day operative mortality results: randomised controlled trial. Lancet 2004;364(9437):843-8.

\section{EVAR 2005}

EVAR trial participants. Endovascular aneurysm repair versus open repair in patients with abdominal aortic aneurysm (EVAR trial 1): randomised controlled trial. Lancet 2005;365(9478):2179-86.

\section{EVAR2 2005}

EVAR trial participants. Endovascular aneurysm repair and outcome in patients unfit for open repair of abdominal aortic aneurysm (EVAR trial 2): randomised controlled trial. Lancet 2005;365(9478):2187-92.

\section{Gorham 2004}

Gorham TJ, Taylor J, Raptis S. Endovascular treatment of abdominal aortic aneurysm. British Journal of Surgery 2004;91(7):815-27.

\section{GRADEpro GDT 2015 [Computer program]}

McMaster University (developed by Evidence Prime, Inc). GRADEpro Guideline Development Tool (GRADEpro GDT). Version 2015. McMaster University (developed by Evidence Prime, Inc), Available from www.gradepro.org. 


\section{Greenhalgh 1998}

Greenhalgh RM, Forbes JF, Fowkes FG, Powell JT, Ruckley CV, Brady AR, et al. Early elective open surgical repair of small abdominal aortic aneurysms is not recommended: results of the UK Small Aneurysm Trial. Steering Committee. European Journal of Vascular and Endovascular Surgery 1998;16(6):462-4.

\section{Harris 2005}

Harris P, Buth J, Eurostar, Beard J, RETA. What is the future for registries on endovascular aneurysm repair and who should be responsible?. European Journal of Vascular and Endovascular Surgery 2005;30(4):343-5.

\section{Higgins 2003}

Higgins JP, Thompson SG, Deeks JT, Altman DG. Measuring inconsistency in meta-analyses. BMJ 2003;327(7414):557-60.

\section{Higgins 2011}

Higgins JPT, Altman DG, Sterne JAC (editors). Chapter 8: Assessing risk of bias in included studies. In: Higgins JPT, Green $\mathrm{S}$ (editors). Cochrane Handbook for Systematic Reviews of Interventions Version 5.1.0 (updated March 2011). The Cochrane Collaboration, 2011. Available from handbook.cochrane.org.

\section{Hinterseher 2004}

Hinterseher I, Saeger HD, Koch R, Bloomenthal A, Ockert D, Bergert $\mathrm{H}$. Quality of life and long-term results after ruptured abdominal aortic aneurysm. European Journal of Vascular and Endovascular Surgery 2004;28(3):262-9.

\section{Huber 1995}

Huber TS, Harward TR, Flynn TC, Albright JL, Seeger JM. Operative mortality rates after elective infrarenal aortic reconstructions. Journal of Vascular Surgery 1995;22(3):287-93.

\section{Jacomelli 2016}

Jacomelli J, Summers L, Stevenson A, Lees T, Earnshaw JJ. Impact of the first 5 years of a national abdominal aortic aneurysm screening programme. British Journal of Surgery 2016;103(9):1125-31.

\section{Karthikesalingam 2014}

Karthikesalingam A, Holt PJ, Vidal-Diez A, Ozdemir BA, Poloniecki JD, Hinchliffe RJ, et al. Mortality from ruptured abdominal aortic aneurysms: clinical lessons from a comparison of outcomes in England and the USA. Lancet 2014;383(9921):963-9.

\section{Korhonen 2004}

Korhonen SJ, Ylonen K, Biancari F, Heikkinen M, Salenius J-P, Lepantalo M, et al. Glasgow Aneurysm Score as a predictor of immediate outcome after surgery for ruptured abdominal aortic aneurysm. British Journal of Surgery 2004;91(11):1449-52.

\section{Lachat 2002}

Lachat ML, Pfammatter T, Wizke HJ, Bettex D, Kunzli A, Wolfensberger $\mathrm{U}$, et al. Endovascular repair with bifurcated stent-grafts under local anaesthesia to improve outcome of ruptured aortoiliac aneurysms. European Journal of Vascular and Endovascular Surgery 2002;23(6):528-36.

\section{Lederle 1997}

Lederle FA, Johnson GR, Wilson SE, Chute EP, Littooy FN, Bandyk $\mathrm{D}$, et al. Prevalence and associations of abdominal aortic aneurysm detected through screening. Aneurysm Detection and Management (ADAM) Veterans Affairs Cooperative Study Group. Annals of Internal Medicine 1997;126(6):441-9.

\section{Lee 2004}

Lee WA, Herniese CM, Tayyarah M, Huber TS, Seeger JM. Impact of endovascular repair on early outcomes of ruptured abdominal aortic aneurysms. Journal of Vascular Surgery 2004;40(2):211-5.

\section{Mani 2009}

Mani K, Björck M, Lundkvist J, Wanhainen A. Improved long-term survival after abdominal aortic aneurysm repair. Circulation 2009;120(3):201-11.

\section{Mani 2011}

Mani K, Lees T, Beiles B, Jensen LP, Venermo M, Simo G, et al. Treatment of abdominal aortic aneurysm in nine countries 2005-2009: a Vascunet report. European Journal of Vascular and Endovascular Surgery 2011;42(5):598-607.

\section{Moll 2011}

Moll FL, Powell JT, Fraedrich G, Verzini F, Haulon S, Waltham M, et al. Management of Abdominal Aortic Aneurysms Clinical Practice Guidelines of the European Society for Vascular Surgery. European Journal of Vascular and Endovascular Surgery 2011;41:S1-S58.

\section{Neary 2003}

Neary WD, Crow P, Foy C, Prytherch D, Heather BP, Earnshaw JJ. Comparison of POSSUM scoring and the Hardman Index in selection of patients for repair of ruptured abdominal aortic aneurysm. British Journal of Surgery 2003;90(4):421-5.

\section{Nordon 2011}

Nordon IM, Hinchliffe RJ, Loftus IM, Tompson MM. Pathophysiology and epidemiology of abdominal aortic aneurysms. Nature Reviews Cardiology 2011;8:92-102.

\section{Norman 2004}

Norman PE, Jamrozik K, Lawrence-Brown MM, Le MT, Spencer CA, Tuohy RJ, et al. Population based randomised controlled trial on impact of screening on mortality from abdominal aortic aneurysm. BMJ 2004;329(7477):1259.

\section{Paravastu 2014}

Paravastu SCV, Jayarajasingam R, Cottam R, Palfreyman SJ, Michaels JA, Thomas SM. Endovascular repair of abdominal aortic aneurysm. Cochrane Database of Systematic Reviews 2014, Issue 1. [DOI: 10.1002/14651858.CD004178.pub2]

\section{Parodi 1991}

Parodi JC, Palmaz JC, Barone HD. Transfemoral intraluminal graft implantation for abdominal aortic aneurysms. Annals of Vascular Surgery 1991;5(6):491-9. 


\section{PIVOTAL Trial}

Ouriel K, Clair DG, Kent KC, Zarins CK, PIVOTAL Investigators. Endovascular repair compared with surveillance for patients with small abdominal aortic aneurysms. Journal of Vascular Surgery 2010;51(5):1081-7.

\section{Powell 2003}

Powell JT. Familial clustering of abdominal aortic aneurysm smoke signals, but no culprit genes. British Journal of Surgery 2003;90(10):1173-4.

\section{Prinssen 2004}

Prinssen M, Verhoeven ELG, Buth J, Cuypers PW, van Sambeek MR, Balm R, et al. A randomized controlled trial comparing conventional and endovascular repair of abdominal aortic aneurysms. New England Journal of Medicine 2004;351(16):1607-18.

\section{Qin 2014}

Qin C, Chen L, Xiao YB. Emergent endovascular vs. open surgery repair for ruptured abdominal aortic aneurysms: a metaanalysis. PLOS ONE 2014;9(1):e87465.

\section{RevMan 2014 [Computer program]}

The Nordic Cochrane Centre, The Cochrane Collaboration. Review Manager (RevMan). Version 5.3. Copenhagen: The Nordic Cochrane Centre, The Cochrane Collaboration, 2014.

\section{Ryan 2016}

Ryan R, Santesso N, Hill S. Preparing Summary of Findings (SoF) tables. Cochrane Consumers and Communication Group (available at cccrg.cochrane.org/author-resources) 2016, issue Version 1.0 June 2016.

\section{Scott 1991}

Scott RA, Ashton, HA, Kay DN. Abdominal aortic aneurysm in 4237 screened patients: prevalence, development and management over 6 years. British Journal of Surgery 1991;78(9):1122-5.

\section{Scott 1995}

Scott RA, Wilson NM, Ashton HA, Kay DN. Influence of screening on the incidence of ruptured abdominal aortic aneurysm: 5year results of a randomized controlled study. British Journal of Surgery 1995;82(8):1066-70.

\section{Svensjö 2011}

Svensjö S, Björck M, Gürtelschmid M, Djavani Gidlund K, Hellberg A, Wanhainen A. Low prevalence of abdominal aortic aneurysm among 65-year-old Swedish men indicates a change in the epidemiology of the disease. Circulation 2011;124(10):1118-23.

\section{Sweeting 2015}

Sweeting MJ, Balm R, Desgranges P, Ulug P, Powell JT. Individual-patient meta-analysis of three randomized trials comparing endovascular versus open repair for ruptured abdominal aortic aneurysm. British Journal of Surgery 2015;102:1229-39.

\section{Sweeting 2015a}

Sweeting MJ, Ulug P, Powell JT, Desgranges P, Balm R. Ruptured Aneurysm Trials: the importance of longer-term outcomes and meta-analysis for 1-year mortality. European Journal of Vascular and Endovascular Surgery 2015;50(3):297-302.

\section{Søgaard 2012}

Søgaard R, Laustsen J, Lindholt JS. Cost effectiveness of abdominal aortic aneurysm screening and rescreening in men in a modern context: evaluation of a hypothetical cohort using a decision analytical model. BMJ 2012;345:e4276.

\section{Takagi 2011}

Takagi H, Umemoto T. A meta-analysis of randomized and riskadjusted observational studies of endovascular versus open repair for ruptured abdominal aortic aneurysm. Vascular and Endovascular Surgery 2011;45(8):717-9.

\section{Tambyraja 2004}

Tambyraja AL, Fraser SC, Murie JA, Chalmers RT. Quality of life after repair of ruptured abdominal aortic aneurysm. European Journal of Vascular and Endovascular Surgery 2004;28(3):229-33.

\section{Thomas 2005}

Thomas SM, Beard JD, Ireland M, Ayers S, Vascular Society of Great Britain and Ireland, British Society of Interventional Radiology. Results from the prospective registry of endovascular treatment of abdominal aortic aneurysms (RETA): mid-term results to five years. European Journal of Vascular and Endovascular Surgery 2005;29(6):563-70.

\section{UK NAAASP}

NHS abdominal aortic aneurysm screening programme. aaa.screening.nhs.uk/ (accessed 21 April 2014).

\section{van Beek 2014}

van Beek SC, Conijn AP, Koelemay MJ, Balm R. Endovascular aneurysm repair versus open repair for patients with a ruptured abdominal aortic aneurysm: a systematic review and metaanalysis of short term survival. European Journal of Vascular and Endovascular Surgery 2014;47(6):593-602.

\section{van Sambeek 2002}

van Sambeek MR, van Dijk LC, Hendriks JM, van Grotel M, Kuiper JW, Pattynama PM, et al. Endovascular versus conventional open repair of acute abdominal aortic aneurysm: feasibility and preliminary results. Journal of Endovascular Therapy 2002;9(4):443-8.

\section{van Vlijmen 2002}

van Vlijmen-van Keulen CJ, Pals G, Rauwerda JA. Familial abdominal aortic aneurysm: a systematic review of a genetic background. European Journal of Vascular and Endovascular Surgery 2002;24(2):105-16.

\section{Veith 2003}

Veith FJ, Ohki T, Lipsitz EC, Suggs WD, Cynamon J. Treatment of ruptured abdominal aortic aneurysms with stent grafts: a new gold standard?. Seminars in Vascular Surgery 2003;16(2):171-5. 


\section{Visser 2007}

Visser JJ, van Sambeek MRHM, Hamza TH, Hunink MGM, Bosch JL. Ruptured abdominal aortic aneurysms: Endovascular repair versus open surgery - systematic review. Radiology 2007;245(1):122-9.

\section{Wilmink 1999}

Wilmink TB, Quick CR, Day NE. The association between cigarette smoking and abdominal aortic aneurysms. Journal of Vascular Surgery 1999;30(6):1099-105.

\section{References to other published versions of this review \\ Badger 2014}

Badger S, Bedenis R, Blair PH, Ellis P, Kee F, Harkin DW. Endovascular treatment for ruptured abdominal aortic

\section{CHARACTERISTICS OF STUDIES}

Characteristics of included studies [ordered by study ID] aneurysm. Cochrane Database of Systematic Reviews 2014, Issue 7. [DOI: 10.1002/14651858.CD005261.pub3]

\section{Dillon 2005}

Dillon M, Blair PH, Cardwell C, Ellis PK, Harkin DW, Kee F. Endovascular treatment for ruptured abdominal aortic aneurysm. Cochrane Database of Systematic Reviews 2005, Issue 2. [DOI: 10.1002/14651858.CD005261]

\section{Dillon 2007}

Dillon M, Cardwell C, Blair PH, Ellis P, Kee F, Harkin DW. Endovascular treatment for ruptured abdominal aortic aneurysm. Cochrane Database of Systematic Reviews 2007, Issue 1. [DOI: 10.1002/14651858.CD005261.pub2]

* Indicates the major publication for the study

\section{AJAX}

Methods Study type: multicentre, randomised controlled trial, intention-to-treat

Study aim: compare EVAR and open repair in treating RAAA on mortality and severe complications Country: Netherlands

Setting: 3 large hospital vascular centres in Amsterdam

Number randomised: total $\mathrm{n}=116($ eEVAR $\mathrm{n}=57$; open repair $\mathrm{n}=59)$

Age (mean years, $95 \% \mathrm{Cl}$ ): eEVAR $=74.5$ (72.3 to 77.5$)$; open repair $=74.5$ (72.2 to 76.8$)$

Gender (M/F): eEVAR = 49/8; open repair = 50/9

Inclusion criteria: male and females over 18 years of age; clinical diagnosis of RAAA; aneurysm accompanied by acute haemorrhage outside of the aortic wall of CTA; suitable for EEVAR and open repair

Exclusion criteria: extension of the aneurysm to juxta- or suprarenal aorta; kidney transplant; horseshoe kidney; allergy to intravenous contrast; connective tissue disease; severe haemodynamic instability prohibiting CT

eEVAR anatomical suitability requirements: suitable infrarenal anchoring segment, minimum length of the infrarenal segment of at least 10 to $15 \mathrm{~mm}$, infrarenal diameter of 20 to $32 \mathrm{~mm}$, no obstructing calcifications, tortuosity of thrombosis, suitable iliac anchoring segment, ipsilateral iliac diameter of 8 to 18 $\mathrm{mm}$, contralateral iliac diameter of 10 to $20 \mathrm{~mm}$, at least 1 iliac artery should be able to accommodate an endograft

CVD risk factors $(n(\%))$ : diabetes (EVAR $n=2(4 \%)$, open repair $n=1(2 \%))$; hypertension (EVAR $n=13$ $(23 \%)$, open repair $n=10(17 \%))$; smoker (EVAR $n=23(40 \%)$, open repair $n=20(34 \%))$; hyperlipidaemia $($ EVAR $n=13(23 \%)$, open repair $n=19(32 \%))$; renal disease (EVAR $n=1(2 \%)$, open repair $n=2(3 \%)$ ); pulmonary disease (EVAR $n=7(12 \%)$, open repair $n=3(5 \%)$ ); carotid disease (EVAR $n=16(28 \%)$, open repair $n=10(17 \%))$; cardiac disease (EVAR $n=16(28 \%)$, open repair $n=14(24 \%)$ )

Type of RAAA: infrarenal 
AJAX (Continued)

Open repair description: midline laparotomy and exclusion of rupture aneurysm by either polyester tube or bifurcated graft; conducted under general anaesthesia

\begin{tabular}{ll}
\hline Outcomes & $\begin{array}{l}\text { Composite death and severe complications at } 30 \text { days' postintervention; long-term mortality rates (6 } \\
\text { months after randomisation); length of hospital and ICU stay; duration of intubation/ventilation; use of } \\
\text { blood products; for EVAR, occurrence of endoleaks }\end{array}$ \\
\hline Notes & $\begin{array}{l}\text { Study period: April } 2004 \text { to February 2011; } 3 \text { main trial centres, all other (7) regional hospitals trans- } \\
\text { ferred participants to one of the trial centres }\end{array}$
\end{tabular}

\section{Risk of bias}

\begin{tabular}{lll}
\hline Bias & Authors' judgement & Support for judgement \\
\hline $\begin{array}{l}\text { Random sequence genera- } \\
\text { tion (selection bias) }\end{array}$ & Low risk & "The randomization sequence was generated by an independent clinical re- \\
& & $\begin{array}{l}\text { search unit using ALEA software for randomization in clinical trials with a 1:1 } \\
\text { allocation using random block sizes of 4 or 6, stratified for each participating } \\
\text { centre." }\end{array}$ \\
\hline
\end{tabular}

\begin{tabular}{ll}
\hline $\begin{array}{l}\text { Allocation concealment } \\
\text { (selection bias) }\end{array}$ & Low risk \\
& "Allocation was concealed using sequentially numbered opaque sealed en- \\
velopes."
\end{tabular}

Blinding of participants Low risk It was not possible to blind surgical team, but unlikely to influence outcomes.
and personnel (perfor-
mance bias)
All outcomes

\begin{tabular}{|c|c|c|}
\hline $\begin{array}{l}\text { Blinding of outcome as- } \\
\text { sessment (detection bias) } \\
\text { All outcomes }\end{array}$ & Low risk & $\begin{array}{l}\text { Double database entry; endpoint adjudication committee blinded; indepen- } \\
\text { dent safety committee blinded }\end{array}$ \\
\hline
\end{tabular}

\begin{tabular}{lll}
\hline $\begin{array}{l}\text { Incomplete outcome data } \\
\text { (attrition bias) } \\
\text { All outcomes }\end{array}$ & Low risk & $\begin{array}{l}\text { All participants accounted for in CONSORT diagram; both treatment groups } \\
\text { had similar dropout rates and reasons. }\end{array}$ \\
\hline $\begin{array}{l}\text { Selective reporting (re- } \\
\text { porting bias) }\end{array}$ & Low risk & All outcomes reported on. \\
\hline Other bias & Low risk & None \\
\hline
\end{tabular}

Study type: multicentre, randomised controlled trial, open label, intention-to-treat
Study aim: to compare postoperative mortality between open surgical repair and endovascular repair
for aorto-iliac abdominal aortic aneurysms in a homogeneous group of patients
Country: France
Setting: 14 locations

$\begin{array}{ll}\text { Participants } & \text { Number randomised: total } n=107 \text { (eEVAR } n=56 \text {; open repair } \mathrm{n}=51 \text { ) } \\ & \text { Age (mean years (range)): eEVAR }=75.0(56.0 \text { to } 96.0) \text {; open repair }=73.8(54.0 \text { to 93.0) } \\ & \text { Gender }(M \%): \text { eEVAR }=91 \% \text {; open repair }=90 \%\end{array}$


ECAR (Continued)

Inclusion criteria: patients had to be haemodynamically stable (systolic blood pressure on arrival $>80$ $\mathrm{mmHg}$ unassisted by high-dose catacholamines; preoperative CT angiography had to prove aortic rupture and document anatomic suitability for open repair or EVAR, aneurysm rupture was defined by the existence of blood outside the aorto-iliac aneurysm wall: retroperitoneal haematoma with peri-aortic blood in the peri-renal space and/or the para-renal space or intraperitoneal haematoma; availability of a qualified surgeon (minimum prerequisite of having carried out 15 EVAR procedures for asymptomatic/symptomatic AAA) and availability of devices and facilities for performing EVAR

Exclusion criteria: see inclusion criteria

Type of RAAA: aorto-iliac

Interventions
OpVAR: aorto-uni-iliac or bifurcated aorto-bi-iliac stent graft; multiple devices used
Optandard operation

Outcomes 30-day mortality; postoperative morbidity (cardiac, pulmonary, digestive, renal, and neurological); length of stay in ICU; amount of blood transfused; 6-month and 1-year mortality and morbidity; complications

Notes Study period: participants enrolled between January 2008 to January 2013

\section{Risk of bias}

\begin{tabular}{|c|c|c|}
\hline Bias & Authors' judgement & Support for judgement \\
\hline $\begin{array}{l}\text { Random sequence genera- } \\
\text { tion (selection bias) }\end{array}$ & High risk & $\begin{array}{l}\text { "Randomization was done by week, synchronously in all centers"; "patients } \\
\text { were treated by OSR during the first week and subsequent odd numbered } \\
\text { weeks, and by EVAR during the second week and subsequent even numbered } \\
\text { weeks"; authors cite this method as suitable, as imposing } 1 \text { method on a sur- } \\
\text { gical team who may be used to performing the other method would bias the } \\
\text { study. }\end{array}$ \\
\hline & & $\begin{array}{l}\text { This is not a form of randomisation, but rather alternation, and is insufficient } \\
\text { to prevent selection bias. }\end{array}$ \\
\hline $\begin{array}{l}\text { Allocation concealment } \\
\text { (selection bias) }\end{array}$ & High risk & Treatment assignment was based on weeks of the study. \\
\hline $\begin{array}{l}\text { Blinding of participants } \\
\text { and personnel (perfor- } \\
\text { mance bias) } \\
\text { All outcomes }\end{array}$ & Low risk & No blinding, but unlikely to affect outcomes \\
\hline
\end{tabular}

\begin{tabular}{|c|c|c|}
\hline $\begin{array}{l}\text { Blinding of outcome as- } \\
\text { sessment (detection bias) } \\
\text { All outcomes }\end{array}$ & Low risk & No blinding, but unlikely to affect outcomes \\
\hline $\begin{array}{l}\text { Incomplete outcome data } \\
\text { (attrition bias) } \\
\text { All outcomes }\end{array}$ & Low risk & All participants accounted for; no participants were lost to follow-up. \\
\hline $\begin{array}{l}\text { Selective reporting (re- } \\
\text { porting bias) }\end{array}$ & Low risk & All predefined outcomes were reported on. \\
\hline Other bias & Unclear risk & $\begin{array}{l}\text { Underpowered: to achieve a power }>80 \% \text { with an alpha risk of } 5 \%, 80 \text { partici- } \\
\text { pants were required in each treatment group. }\end{array}$ \\
\hline
\end{tabular}




Study type: single centre, randomised controlled trial, open label, intention-to-treat
Study aim: to test the hypothesis that EVAR can reduce the perioperative mortality associated with rup-
tured AAA compared with open repair
Country: England
Setting: hospital

Inclusion criteria: all patients admitted with clinically suspected or radiologically confirmed rupture of an infrarenal abdominal aortic aneurysm that in the opinion of the duty consultant vascular surgeon would normally be treated with open repair

Exclusion criteria: no endovascular team available; full selection of emergency stent-grafts not available; age < 50 years; inability to give verbal or written consent; unconscious patient; allergy to radiological contrast, stainless steel, or polyester; severe comorbidity that would preclude intensive care treatment following open repair; previous endovascular AAA repair; women of childbearing potential not taking contraception; pregnant and lactating women

eEVAR anatomical suitability (exclusion criteria): absolute contraindications: no evidence on aneurysm rupture, juxtarenal aneurysm, neck diameter $>32 \mathrm{~mm}$, external iliac artery diameter $>6 \mathrm{~mm}$; relative contraindications: proximal neck length $<10 \mathrm{~mm}$, excessive thrombus in the proximal neck, common iliac artery length $<25 \mathrm{~mm}$, heavily calcified iliac arteries

CVD risk factors $(n(\%))$ : ischaemic heart disease (eEVAR $=3(20 \%)$, open repair $=5(29 \%))$; chronic obstructive airways disease (eEVAR $=0(0 \%)$, open repair $=3(18 \%))$; peripheral vascular disease (eEVAR = $1(7 \%)$, open repair $=2(12 \%))$; renal disease $(\mathrm{eEVAR}=1(7 \%)$, open repair $=2(12 \%))$; hypertension $(\mathrm{eE}-$ VAR $=5(29 \%)$, open repair $=8(47 \%))$; active smoker $($ eEVAR $=4(27 \%)$, open repair $=6(35 \%))$; ex-smoker $($ eEVAR $=8(53 \%)$, open repair $=3(18 \%))$; known AAA (eEVAR $=3(20 \%)$, open repair $=7(41 \%))$

Type of RAAA: infrarenal

eEVAR description: Those with a diagnostic CT were transferred directly to operating theatre, and those without a diagnostic CT first had a CT scan to determine aortic measurement; performed in dedicated vascular operating theatre using a Siremobil 2000 image intensifier, with digital subtraction angiography facilities; most participants heparinised; 2-piece aorto-uni-iliac stent-graft made with Gianturco stents with uncovered suprarenal component; occluding device used in contralateral common iliac artery; after deployment of stent-graft, a femoro-femoral crossover graft was performed

Open-repair description: After randomisation to open repair, participants were transferred directly to the operating theatre, per local practice; performed transperitoneally either by midline or transverse incisions; aorta clamped below renal arteries; participants not heparinised; inlay technique was used and grafts were gelatin-coated polyester

Outcomes Perioperative mortality (defined as 30-day or in-hospital), complications

Notes "Patients were deemed suitable for EVAR if, in the opinion of the operating surgeon, they could perform the repair"; participants recruited September 2002 to December 2004; 5 surgeons on unit, required that available surgeon and team had sufficient expertise to offer EVAR; if not, conventional open repair was offered; unstable patients that might be disadvantaged by delay incurred by CT scan could, at the surgeon's discretion, not be randomised and taken directly for open repair

\section{Risk of bias}


Hinchliffe 2006 (Continued)

\section{Bias Authors' judgement Support for judgement}

Random sequence genera- Unclear risk

tion (selection bias)

"Randomisation was then performed from sealed opaque envelopes kept in the Accident and Emergency Department". Unclear how randomisation sequence was generated

\begin{tabular}{|c|c|c|}
\hline $\begin{array}{l}\text { Allocation concealment } \\
\text { (selection bias) }\end{array}$ & Low risk & $\begin{array}{l}\text { "Randomisation was then performed from sealed opaque envelopes kept in } \\
\text { the Accident and Emergency Department" }\end{array}$ \\
\hline $\begin{array}{l}\text { Blinding of participants } \\
\text { and personnel (perfor- } \\
\text { mance bias) } \\
\text { All outcomes }\end{array}$ & Low risk & $\begin{array}{l}\text { Due to the nature of the intervention the study was unblinded, but unlikely } \\
\text { to influence outcomes. "The surgeons were blinded to the dimensions of pa- } \\
\text { tient's aorta until randomisation had taken place" to avoid bias. }\end{array}$ \\
\hline $\begin{array}{l}\text { Blinding of outcome as- } \\
\text { sessment (detection bias) } \\
\text { All outcomes }\end{array}$ & Low risk & $\begin{array}{l}\text { Not possible to blind team regarding allocation group, but unlikely to influ- } \\
\text { ence outcome measures }\end{array}$ \\
\hline $\begin{array}{l}\text { Incomplete outcome data } \\
\text { (attrition bias) } \\
\text { All outcomes }\end{array}$ & Low risk & $\begin{array}{l}\text { All participants accounted for; crossover patients accounted for; similar } \\
\text { dropout rates and reasons for dropout between treatment groups }\end{array}$ \\
\hline $\begin{array}{l}\text { Selective reporting (re- } \\
\text { porting bias) }\end{array}$ & Low risk & $\begin{array}{l}\text { Most of protocol outlined in the text; all relevant outcomes reported; with the } \\
\text { exception of mortality, outcomes are not well described in the methods }\end{array}$ \\
\hline Other bias & Unclear risk & Underpowered study: 32 of the required 100 participants recruited \\
\hline
\end{tabular}

\section{IMPROVE}

Methods Study type: multicentre, randomised controlled trial, open label, intention-to-treat

Study aim: to assess whether EVAR versus open repair reduces early mortality for people with suspected RAAA

Country: UK and Canada

Setting: 30 hospital vascular units and specialist centres

Participants

Number randomised: total $\mathrm{n}=613($ eEVAR $\mathrm{n}=316$; open repair $\mathrm{n}=297)$

Age $($ mean years $( \pm$ SD)): eEVAR $=76.7(7.4)$; open repair $=76.7(7.8)$

Gender (M/F): eEVAR = 246/70; open repair = 234/63

Inclusion criteria: men and women over the age of 50 years; clinical diagnosis of RAAA or ruptured aorto-iliac aneurysm, made by a senior trial hospital clinician

Exclusion criteria: previous aneurysm repair; rupture of an isolated internal iliac aneurysm, aorto-caval or aorto-enteric fistulae; recent anatomical assessment of the aorta; connective tissue disorder; if intervention was considered to be futile

eEVAR anatomical suitability requirements: no absolute requirements will be set for the study, but proximal neck morphology with a diameter exceeding $32 \mathrm{~mm}$ or a length less than $10 \mathrm{~mm}$ may be considered unfavourable, and iliac artery diameters should be in the range of 8 to $22 \mathrm{~mm}$

CVD risk factors ( $\mathrm{n}(\%))$ : not given

Type of RAAA: "ruptured AAA or ruptured aortoiliac aneurysm" 
IMPROVE (Continued)

Interventions
eEVAR description: endovascular supracoeliac aortic balloon occlusion will be used to support less stable patients; most interventions performed with aorto-uni-iliac graft, but some participants received bifurcated grafts, with subsequent femoro-femoral crossover graft with contralateral iliac occlusion; control of aorta achieved using local/region anaesthesia, with general anaesthesia used later in procedure if necessary

Open-repair description: CT scan is optional; aneurysms repaired by cross-clamping the proximal aorta and inserting a prosthetic inlay graft; performed under general anaesthesia 30-day mortality, 24-hour and in-hospital mortality, costs, re-interventions at primary admission time and place of discharge, cost-effectiveness, and mortality at 12 months

Notes Participants recruited September 2009 to July 2013; flow diagram shows 623 randomised, but 10 were excluded after data monitoring committee reviewed participants, 613 used in analysis; only 275 (87\%) of EVAR and $261(88 \%)$ of open repair had confirmed RAAA.

\section{Risk of bias}

\begin{tabular}{lll}
\hline Bias & Authors' judgement & Support for judgement \\
\hline $\begin{array}{l}\text { Random sequence genera- } \\
\text { tion (selection bias) }\end{array}$ & Low risk & $\begin{array}{l}\text { "An independent contractor provided telephone randomisation, with comput- } \\
\text { er generated assignation of patients in a 1:1 ratio, using variable block size and } \\
\text { stratified by centre." }\end{array}$ \\
\hline
\end{tabular}

\begin{tabular}{ll}
\hline $\begin{array}{l}\text { Allocation concealment } \\
\text { (selection bias) }\end{array}$ & Low risk \\
& er generated assignation of patients ..."
\end{tabular}

\begin{tabular}{ll}
\hline $\begin{array}{l}\text { Blinding of participants } \\
\text { and personnel (perfor- }\end{array}$ & Low risk \\
mance & It was not possible to blind the surgical team, but this was unlikely to influence \\
outcomes.
\end{tabular}
mance bias)

All outcomes

\begin{tabular}{|c|c|c|}
\hline $\begin{array}{l}\text { Blinding of outcome as- } \\
\text { sessment (detection bias) } \\
\text { All outcomes }\end{array}$ & Low risk & $\begin{array}{l}\text { Data verification performed centrally at the trial core laboratory; it was unclear } \\
\text { if there was blinding, but this was unlikely to influence outcomes. }\end{array}$ \\
\hline
\end{tabular}

All outcomes

\begin{tabular}{lll}
\hline $\begin{array}{l}\text { Incomplete outcome data } \\
\text { (attrition bias) } \\
\text { All outcomes }\end{array}$ & Low risk & $\begin{array}{l}\text { All participants accounted for, with both treatment groups having similar } \\
\text { dropout rates/reasons for dropouts. }\end{array}$ \\
\hline $\begin{array}{l}\text { Selective reporting (re- } \\
\text { porting bias) }\end{array}$ & Low risk & All pre-described outcomes reported on. \\
\hline Other bias & Low risk & None \\
\hline
\end{tabular}

AAA: abdominal aortic aneurysm

$\mathrm{Cl}$ : confidence interval

CT: computed tomography

CTA: computed tomography angiography

CVD: cardiovascular disease

eEVAR: emergency endovascular aneurysm repair

EVAR: endovascular aneurysm repair

ICU: intensive care unit

IQR: interquartile range

RAAA: ruptured abdominal aortic aneurysm

SD: standard deviation 
Characteristics of excluded studies [ordered by study ID]

\begin{tabular}{ll}
\hline Study & Reason for exclusion \\
\hline Peppelenbosch 2003 & $\begin{array}{l}\text { Prospective study of } 40 \text { consecutive patients with symptomatic AAA or RAAA in whom eEVAR was } \\
\text { the preferential management compared with } 28 \text { historical controls who underwent open repair for } \\
\text { symptomatic AAA or RAAA }\end{array}$ \\
\hline Resch 2003 & $\begin{array}{l}\text { Prospective study of } 21 \text { people with RAAA undergoing eEVAR (1997 to 2002). Retrospective analy- } \\
\text { sis to evaluate why } 23 \text { patients underwent open repair compared to 14 contemporaneous patients } \\
\text { who underwent eEVAR for RAAA (2001 to 2002) }\end{array}$ \\
\hline Rödel 2012 & $\begin{array}{l}\text { Prospective, non-randomised study of 117 consecutive patients presenting with RAAA; } 35 \text { treated } \\
\text { with eEVAR, the remainder treated with open repair(2006 to 2010) }\end{array}$ \\
\hline Verhoeven 2002 & $\begin{array}{l}\text { Prospective study of } 47 \text { patients with acute AAA (RAAA and symptomatic); } 16 \text { underwent eEVAR } \\
\text { compared to open-surgical cohort }\end{array}$ \\
\hline Visser 2006 & $\begin{array}{l}\text { Part prospective, part retrospective, non-randomised study of } 55 \text { consecutive RAAA patients; } 26 \text { un- } \\
\text { derwent eEVAR and } 29 \text { underwent open repair(2001 to 2005) }\end{array}$ \\
\hline
\end{tabular}

AAA: abdominal aortic aneurysm

eEVAR: emergency endovascular aneurysm repair

RAAA: ruptured abdominal aortic aneurysm

\section{DATA AND ANALYSES}

Comparison 1. Emergency endovascular aneurysm repair versus open repair

\begin{tabular}{|c|c|c|c|c|}
\hline Outcome or subgroup title & No. of studies & $\begin{array}{l}\text { No. of partici- } \\
\text { pants }\end{array}$ & Statistical method & Effect size \\
\hline $\begin{array}{l}1 \text { Short-term mortality (30-day or } \\
\text { in-hospital) }\end{array}$ & 4 & 868 & $\begin{array}{l}\text { Odds Ratio (M-H, Fixed, 95\% } \\
\mathrm{Cl})\end{array}$ & $0.88[0.66,1.16]$ \\
\hline 2 Major complications - 30-day & 2 & 223 & $\begin{array}{l}\text { Odds Ratio (M-H, Fixed, 95\% } \\
\mathrm{Cl})\end{array}$ & $0.72[0.42,1.23]$ \\
\hline $\begin{array}{l}3 \text { Complication - Myocardial infarc- } \\
\text { tion }\end{array}$ & 2 & 139 & $\begin{array}{l}\text { Odds Ratio (M-H, Fixed, 95\% } \\
\mathrm{Cl})\end{array}$ & $2.38[0.34,16.53]$ \\
\hline 4 Complication - Stroke & 2 & 148 & $\begin{array}{l}\text { Odds Ratio (M-H, Fixed, 95\% } \\
\mathrm{Cl})\end{array}$ & $0.71[0.12,4.31]$ \\
\hline $\begin{array}{l}5 \text { Complication - Cardiac complica- } \\
\text { tions (moderate or severe) }\end{array}$ & 3 & 253 & $\begin{array}{l}\text { Odds Ratio (M-H, Fixed, 95\% } \\
\mathrm{Cl})\end{array}$ & $0.84[0.32,2.23]$ \\
\hline $\begin{array}{l}6 \text { Complication - Renal complica- } \\
\text { tions (moderate or severe) }\end{array}$ & 3 & 255 & $\begin{array}{l}\text { Odds Ratio (M-H, Random, } \\
95 \% \mathrm{Cl})\end{array}$ & $1.07[0.21,5.42]$ \\
\hline $\begin{array}{l}7 \text { Complication - Respiratory fail- } \\
\text { ure }\end{array}$ & 1 & & $\begin{array}{l}\text { Odds Ratio (M-H, Fixed, 95\% } \\
\mathrm{Cl})\end{array}$ & Totals not selected \\
\hline
\end{tabular}




\begin{tabular}{|c|c|c|c|c|}
\hline Outcome or subgroup title & No. of studies & $\begin{array}{l}\text { No. of partici- } \\
\text { pants }\end{array}$ & Statistical method & Effect size \\
\hline 8 Complication - Bowel ischaemia & 2 & 223 & $\begin{array}{l}\text { Odds Ratio (M-H, Fixed, 95\% } \\
\mathrm{Cl} \text { ) }\end{array}$ & $0.37[0.14,0.94]$ \\
\hline $\begin{array}{l}9 \text { Complication - Spinal cord is- } \\
\text { chaemia }\end{array}$ & 1 & & $\begin{array}{l}\text { Odds Ratio (M-H, Fixed, 95\% } \\
\mathrm{Cl})\end{array}$ & Totals not selected \\
\hline 10 Complication - Reoperation & 2 & 148 & $\begin{array}{l}\text { Odds Ratio (M-H, Fixed, 95\% } \\
\mathrm{Cl})\end{array}$ & $0.89[0.39,2.01]$ \\
\hline 11 Complication - Amputation & 2 & 223 & $\begin{array}{l}\text { Odds Ratio (M-H, Fixed, 95\% } \\
\mathrm{Cl})\end{array}$ & $0.16[0.02,1.32]$ \\
\hline 12 Mortality - 6 months & 1 & & $\begin{array}{l}\text { Odds Ratio (M-H, Fixed, 95\% } \\
\mathrm{Cl})\end{array}$ & Totals not selected \\
\hline 13 Major complications - 6 months & 1 & & $\begin{array}{l}\text { Odds Ratio (M-H, Fixed, 95\% } \\
\mathrm{CI})\end{array}$ & Totals not selected \\
\hline $\begin{array}{l}14 \text { Complication - Reoperation - } 6 \\
\text { months }\end{array}$ & 1 & & $\begin{array}{l}\text { Odds Ratio (M-H, Fixed, 95\% } \\
\mathrm{Cl})\end{array}$ & Totals not selected \\
\hline 15 Mortality - 1 year & 1 & & $\begin{array}{l}\text { Odds Ratio (M-H, Fixed, 95\% } \\
\mathrm{Cl} \text { ) }\end{array}$ & Totals not selected \\
\hline 16 Cost per patient - 30-day & 1 & & $\begin{array}{l}\text { Mean Difference (IV, Fixed, 95\% } \\
\mathrm{CI} \text { ) }\end{array}$ & Totals not selected \\
\hline
\end{tabular}

Analysis 1.1. Comparison 1 Emergency endovascular aneurysm repair versus open repair, Outcome 1 Short-term mortality (30-day or in-hospital).

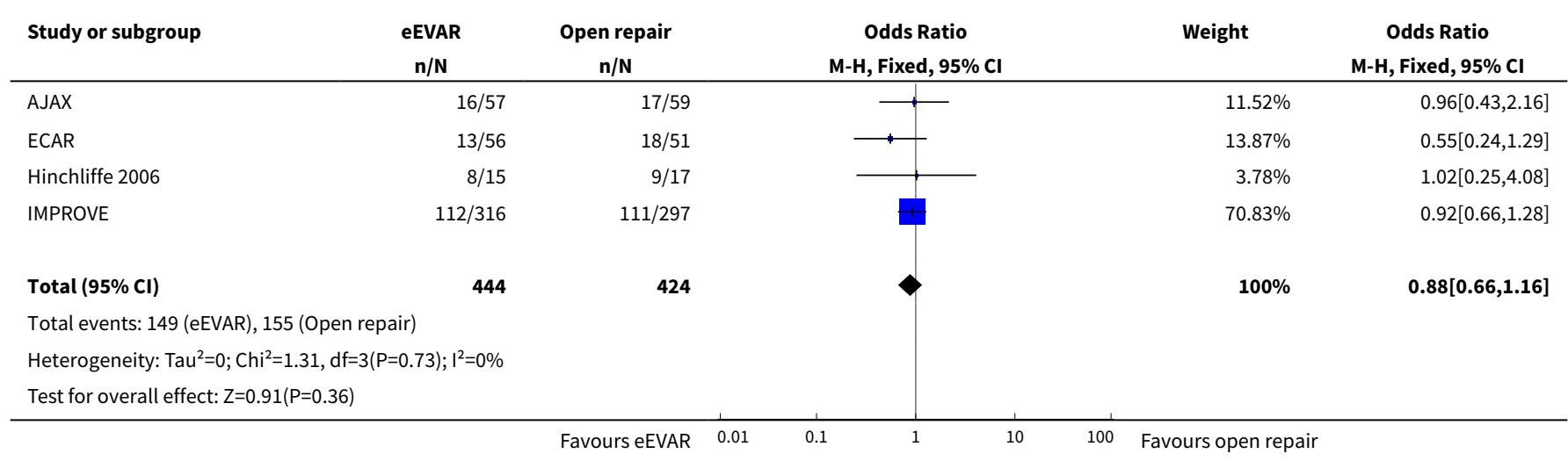


Analysis 1.2. Comparison 1 Emergency endovascular aneurysm repair versus open repair, Outcome 2 Major complications - 30-day.

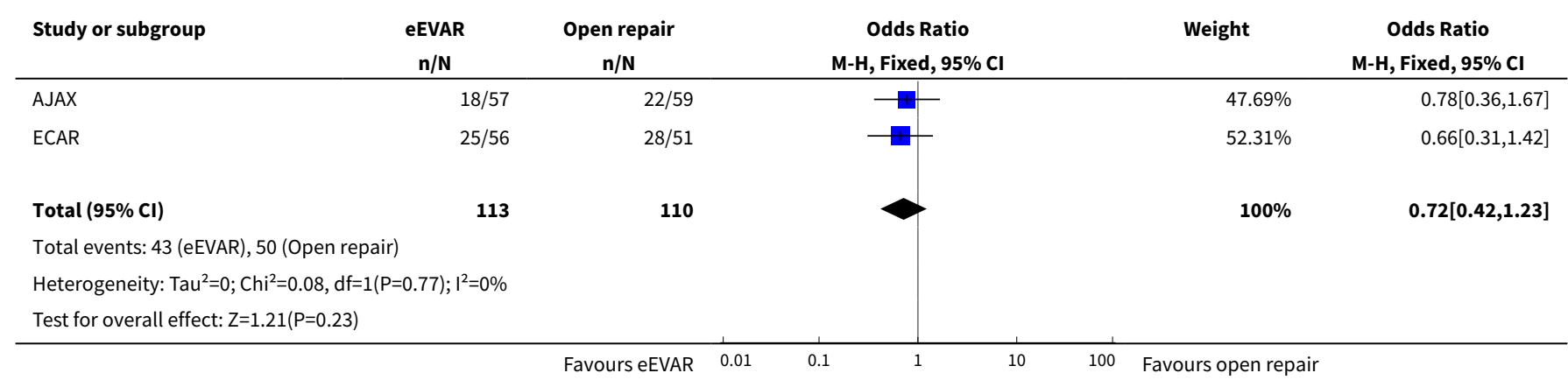

Analysis 1.3. Comparison 1 Emergency endovascular aneurysm repair versus open repair, Outcome 3 Complication - Myocardial infarction.

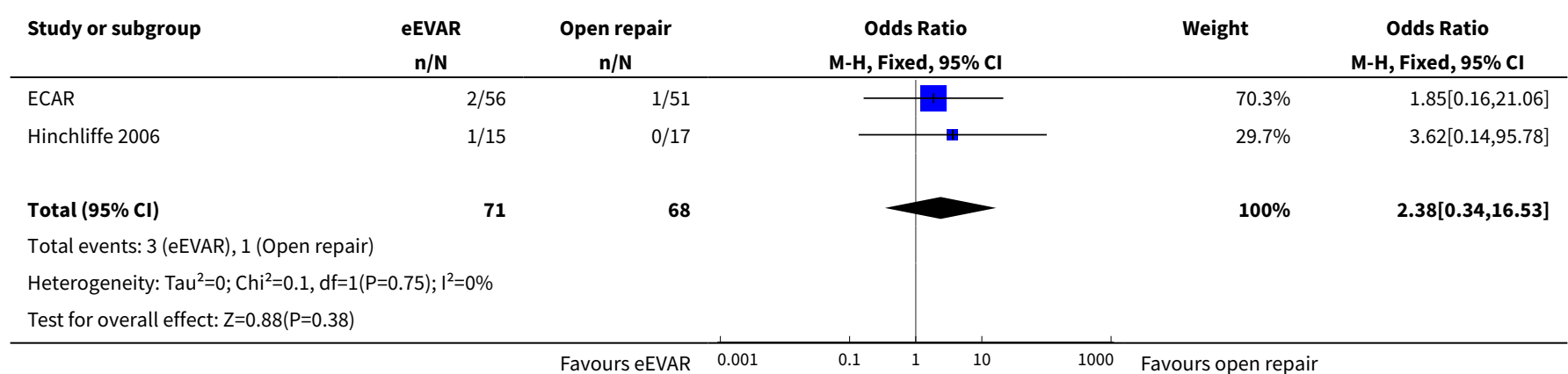

Analysis 1.4. Comparison 1 Emergency endovascular aneurysm repair versus open repair, Outcome 4 Complication - Stroke.

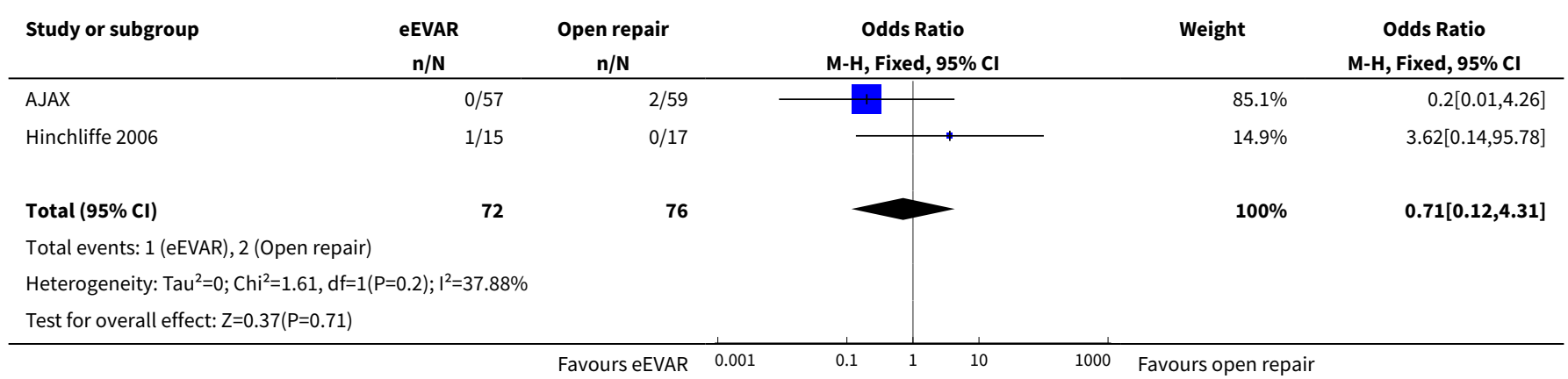


Analysis 1.5. Comparison 1 Emergency endovascular aneurysm repair versus open repair, Outcome 5 Complication - Cardiac complications (moderate or severe).

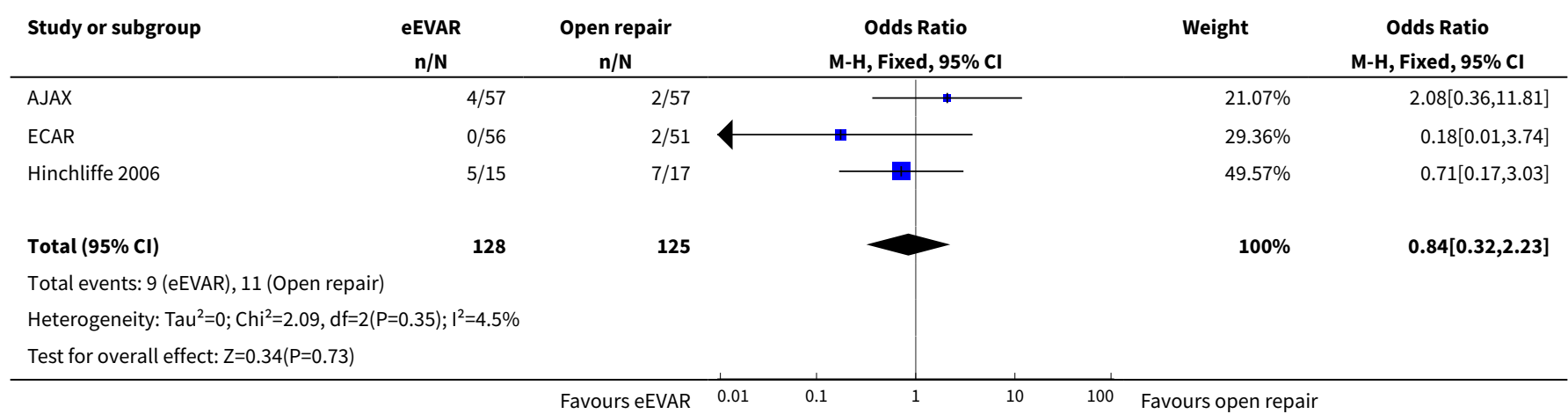

Analysis 1.6. Comparison 1 Emergency endovascular aneurysm repair versus open repair, Outcome 6 Complication - Renal complications (moderate or severe).

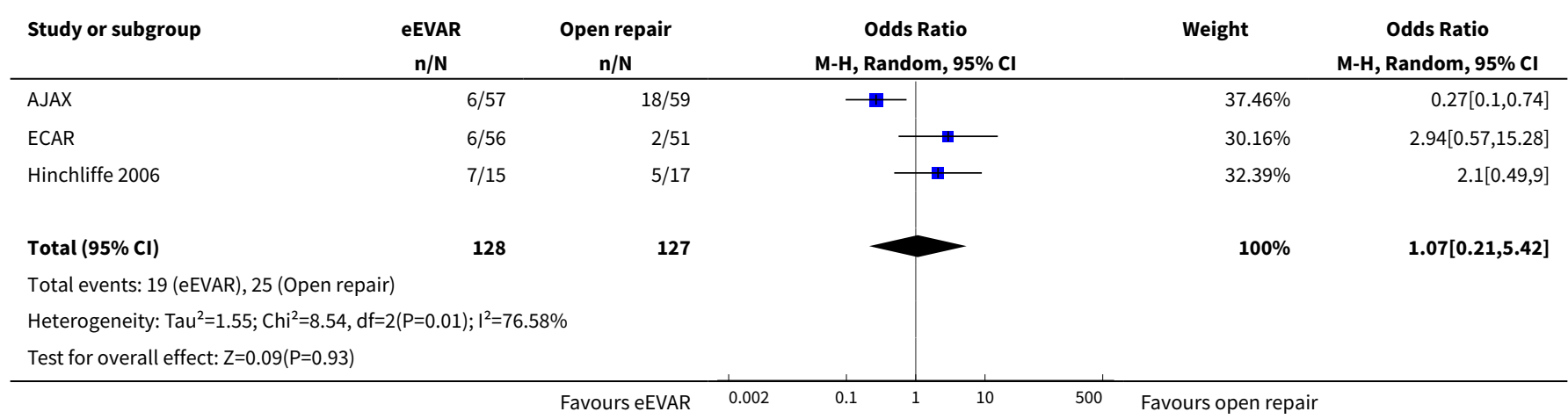

Analysis 1.7. Comparison 1 Emergency endovascular aneurysm repair versus open repair, Outcome 7 Complication - Respiratory failure.

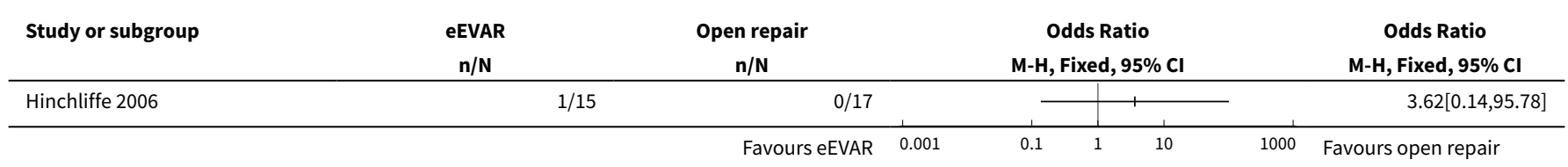

Analysis 1.8. Comparison 1 Emergency endovascular aneurysm repair versus open repair, Outcome 8 Complication - Bowel ischaemia.

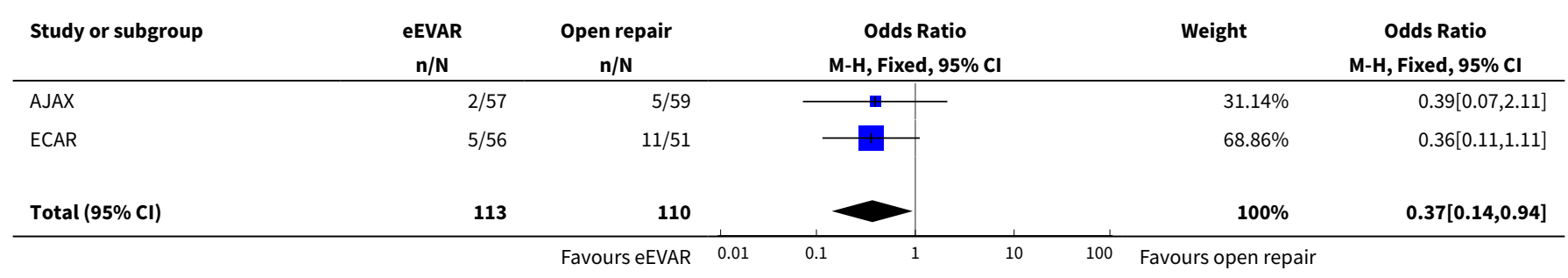




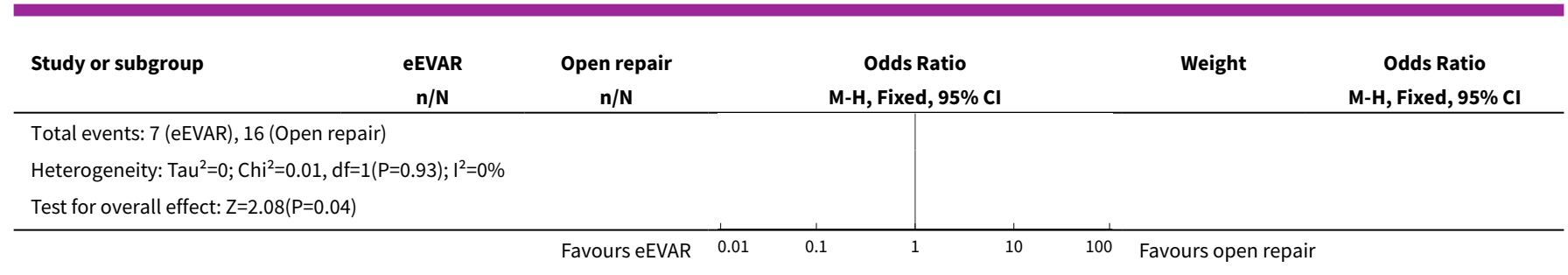

Analysis 1.9. Comparison 1 Emergency endovascular aneurysm repair versus open repair, Outcome 9 Complication - Spinal cord ischaemia.

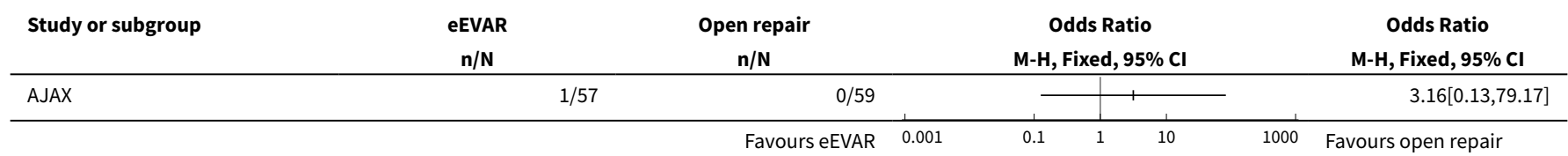

Analysis 1.10. Comparison 1 Emergency endovascular aneurysm repair versus open repair, Outcome 10 Complication - Reoperation.

\begin{tabular}{|c|c|c|c|c|c|}
\hline Study or subgroup & $\begin{array}{c}\text { eEVAR } \\
\mathrm{n} / \mathrm{N}\end{array}$ & $\begin{array}{c}\text { Open repair } \\
n / N\end{array}$ & $\begin{array}{c}\text { Odds Ratio } \\
\text { M-H, Fixed, } 95 \% \mathrm{Cl}\end{array}$ & Weight & $\begin{array}{c}\text { Odds Ratio } \\
\text { M-H, Fixed, } 95 \% \mathrm{Cl}\end{array}$ \\
\hline AJAX & $13 / 57$ & $12 / 59$ & - & $74.04 \%$ & $1.16[0.48,2.81]$ \\
\hline Hinchliffe 2006 & $0 / 15$ & $3 / 17$ & $\begin{array}{l} \\
\end{array}$ & $25.96 \%$ & $0.13[0.01,2.82]$ \\
\hline Total $(95 \% \mathrm{CI})$ & 72 & 76 & & $100 \%$ & $0.89[0.39,2.01]$ \\
\hline \multicolumn{6}{|c|}{ Total events: 13 (eEVAR), 15 (Open repair) } \\
\hline \multicolumn{6}{|c|}{ Test for overall effect: $\mathrm{Z}=0.28(\mathrm{P}=0.78)$} \\
\hline
\end{tabular}

Analysis 1.11. Comparison 1 Emergency endovascular aneurysm repair versus open repair, Outcome 11 Complication - Amputation.

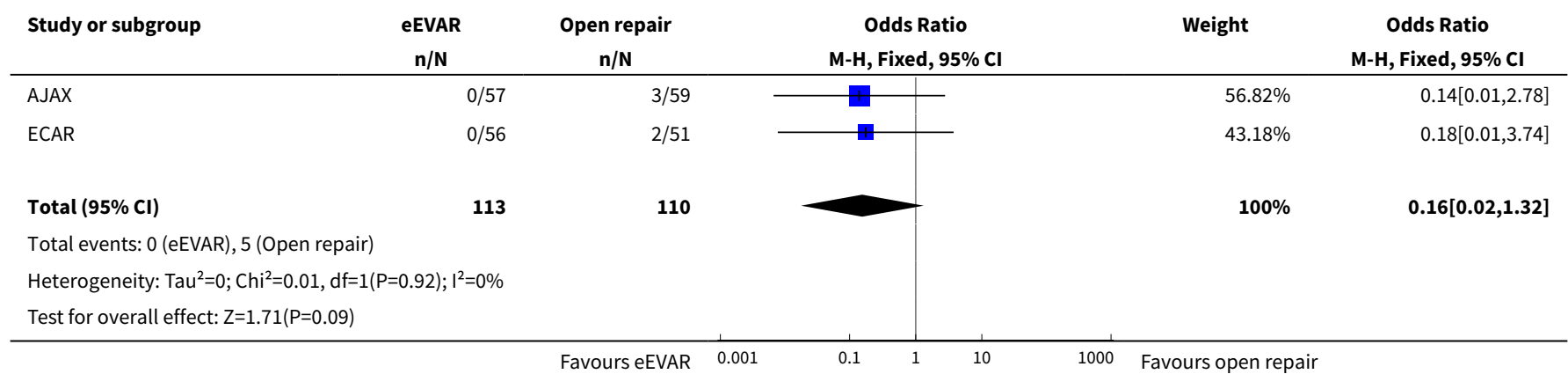


Analysis 1.12. Comparison 1 Emergency endovascular aneurysm repair versus open repair, Outcome 12 Mortality - 6 months.

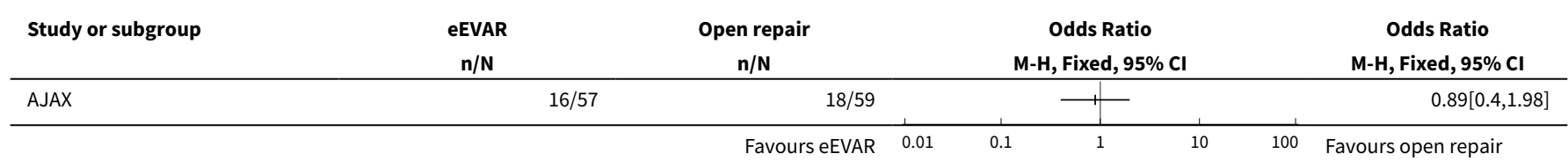

Analysis 1.13. Comparison 1 Emergency endovascular aneurysm repair versus open repair, Outcome 13 Major complications - 6 months.

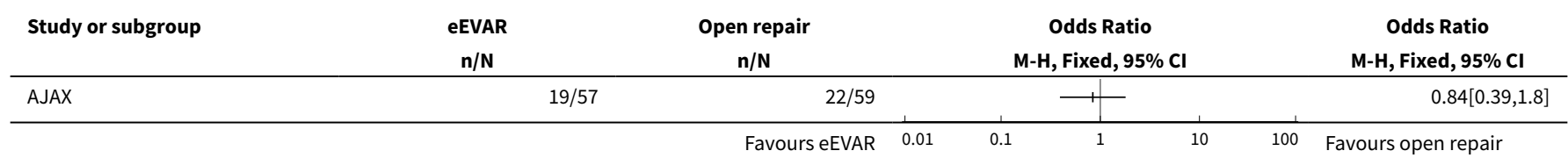

Analysis 1.14. Comparison 1 Emergency endovascular aneurysm repair versus open repair, Outcome 14 Complication - Reoperation - 6 months.

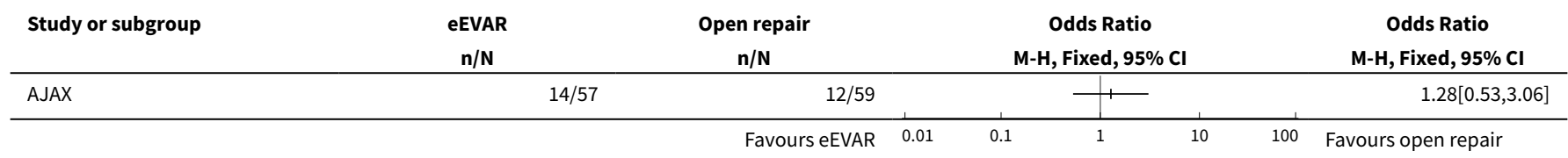

Analysis 1.15. Comparison 1 Emergency endovascular aneurysm repair versus open repair, Outcome 15 Mortality - 1 year.

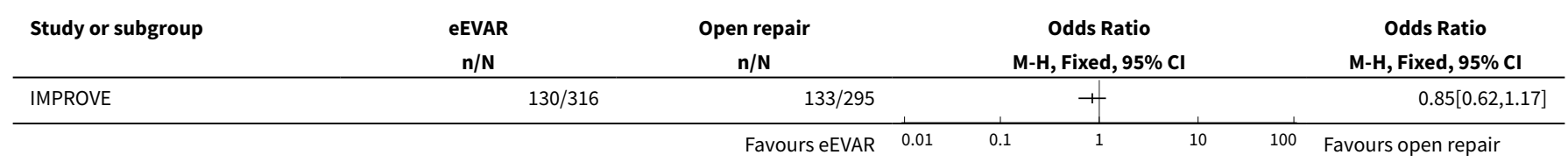

Analysis 1.16. Comparison 1 Emergency endovascular aneurysm repair versus open repair, Outcome 16 Cost per patient - 30-day.

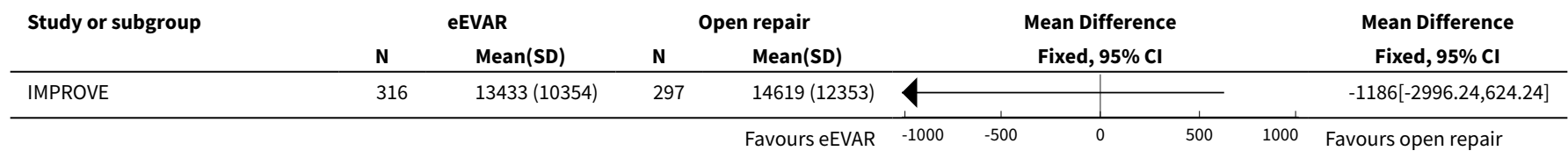

\section{ADDITIONAL TABLES}


Table 1. Perioperative and postoperative participant characteristics

\begin{tabular}{|c|c|c|c|c|c|}
\hline & & $\begin{array}{l}\text { AJAX } \\
\text { (median, IQR) }\end{array}$ & $\begin{array}{l}\text { ECAR } \\
\text { (mean, range) }\end{array}$ & $\begin{array}{l}\text { Hinchliffe } 2006 \\
\text { (median, IQR) }\end{array}$ & $\begin{array}{l}\text { IMPROVE } \\
\text { (mean, SD) }\end{array}$ \\
\hline \multirow{2}{*}{$\begin{array}{l}\text { Time waiting } \\
\text { for procedure }\end{array}$} & eEVAR & $74 \min$ (39 to $126 \mathrm{~min}$ ) & 2.9 hours & - & $93 \min ( \pm 370)$ \\
\hline & Open repair & $45 \mathrm{~min}$ ( 35 to $70 \mathrm{~min})$ & 1.3 hours & - & $73 \min ( \pm 157)$ \\
\hline \multirow[t]{2}{*}{$\begin{array}{l}\text { Time in oper- } \\
\text { ating theatre }\end{array}$} & eEVAR & $185 \mathrm{~min}$ (160 to $236 \mathrm{~min})$ & - & $\begin{array}{l}160 \min (150 \text { to } 234 \\
\min )\end{array}$ & $\begin{array}{l}156 \min ( \pm \\
100)\end{array}$ \\
\hline & Open repair & $157 \min (136$ to $194 \mathrm{~min})$ & - & $\begin{array}{l}150 \min \text { (141 to } 204 \\
\min \text { ) }\end{array}$ & $\begin{array}{l}180 \min ( \pm \\
107)\end{array}$ \\
\hline \multirow[t]{2}{*}{$\begin{array}{l}\text { Blood loss } \\
\text { during opera- } \\
\text { tion }\end{array}$} & eEVAR & $500 \mathrm{~mL}$ (200 to $1375 \mathrm{~mL}$ ) & $\begin{array}{l}\text { Units for transfusion: } \\
6.8 \text { (range } 0 \text { to } 25.0 \text { ) }\end{array}$ & $\begin{array}{l}200 \mathrm{~mL} \text { (163 to } 450 \\
\mathrm{~mL} \text { ) }\end{array}$ & - \\
\hline & Open repair & $3500 \mathrm{~mL}$ (1000 to $4600 \mathrm{~mL}$ ) & $\begin{array}{l}\text { Units for transfusion: } \\
10.9 \text { (range } 0 \text { to } 53.0 \text { ) }\end{array}$ & $\begin{array}{l}2100 \mathrm{~mL} \text { (1150 to } 3985 \\
\mathrm{~mL})\end{array}$ & - \\
\hline \multirow[t]{2}{*}{$\begin{array}{l}\text { Length of } \\
\text { hospital stay }\end{array}$} & eEVAR & 9 days ( 4 to 21 days) & 14.3 days ( 6.0 to 99.0 ) & 10 days ( 6 to 28 days) & $\begin{array}{l}9.8 \text { days }( \pm \\
9.0)\end{array}$ \\
\hline & Open repair & 13 days (5 to 21 days) & 17.1 days (9.1 to 81.1 ) & 12 days (4 to 52 days) & $\begin{array}{l}12.2 \text { days }( \pm \\
10.2)\end{array}$ \\
\hline
\end{tabular}

eEVAR: emergency endovascular aneurysm repair

IQR: interquartile range

SD: standard deviation

\section{APPEN DICES}

\section{Appendix 1. CENTRAL search strategy}

\begin{tabular}{|c|c|c|}
\hline$\# 1$ & MESH DESCRIPTOR Aneurysm, Ruptured EXPLODE ALL TREES & 154 \\
\hline$\# 2$ & MESH DESCRIPTOR Aneurysm, Dissecting & 64 \\
\hline$\# 3$ & MESH DESCRIPTOR Aorta EXPLODE ALL TREES WITH QUALIFIERS SU & 310 \\
\hline$\# 4$ & 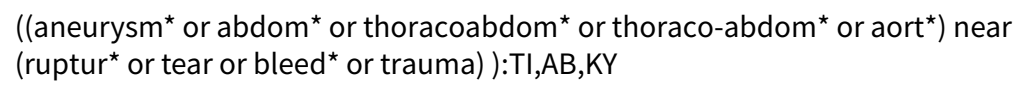 & 790 \\
\hline \#5 & RAAA:TI,AB,KY & 8 \\
\hline \#6 & $\# 1$ OR \#2 OR \#3 OR \#4 OR \#5 & 1137 \\
\hline$\# 7$ & MESH DESCRIPTOR Endovascular Procedures EXPLODE ALL TREES & 6264 \\
\hline \#8 & MESH DESCRIPTOR Stents EXPLODE ALL TREES & 3132 \\
\hline
\end{tabular}


(Continued)

\begin{tabular}{|c|c|c|}
\hline \#9 & MESH DESCRIPTOR Vascular Surgical Procedures & 523 \\
\hline \#10 & MESH DESCRIPTOR Blood Vessel Prosthesis EXPLODE ALL TREES & 406 \\
\hline \#11 & MESH DESCRIPTOR Blood Vessel Prosthesis Implantation EXPLODE ALL TREES & 389 \\
\hline \#12 & endovasc ${ }^{\star}: T I, A B, K Y$ & 1224 \\
\hline \#13 & endostent ${ }^{\star}: \mathrm{TI}, \mathrm{AB}, \mathrm{KY}$ & 1 \\
\hline \#14 & endoluminal:TI,AB,KY & 125 \\
\hline \#15 & endoprosthe ${ }^{\star}: \mathrm{TI}, \mathrm{AB}, \mathrm{KY}$ & 236 \\
\hline \#16 & (graft or endograft $^{\star}$ ):TI,AB,KY & 12927 \\
\hline \#17 & percutaneous ${ }^{\star}: T I, A B, K Y$ & 9399 \\
\hline \#18 & stent $^{\star}: \mathrm{TI}, \mathrm{AB}, \mathrm{KY}$ & 6994 \\
\hline \#19 & $\begin{array}{l}\text { (Palmaz or Zenith or Dynalink or Hemobahn or Luminex }{ }^{\star} \text { or Memotherm or } \\
\text { Wallstent):TI,AB,KY }\end{array}$ & 332 \\
\hline \#20 & (Viabahn or Nitinol or Intracoil or Tantalum):TI,AB,KY & 242 \\
\hline \#21 & EVAR:TI,AB,KY & 100 \\
\hline \#22 & EVRAR:TI,AB,KY & 0 \\
\hline \#23 & TEVAR:TI,AB,KY & 24 \\
\hline \#24 & $\begin{array}{l}\# 7 \text { OR \#8 OR \#9 OR \#10 OR \#11 OR \#12 OR \#13 OR \#14 OR \#15 OR \#16 OR \#17 OR } \\
\# 18 \text { OR \#19 OR \#20 OR \#21 OR \#22 OR \#23 }\end{array}$ & 29429 \\
\hline \#25 & \#6 AND \#24 & 348 \\
\hline \#26 & * NOT SR-PVD:CC AND 31/03/2014 TO 31/07/2016:DL & 186054 \\
\hline$\# 27$ & \#25 AND \#26 & 94 \\
\hline
\end{tabular}

\section{Appendix 2. Trial registries search strategies}

World Health Organization International Clinical Trials Registry Platform (WHO ICTRP)

9 records for 7 trials found for: ruptured and abdominal and aneurysm

ClinicalTrials.gov

67 studies found for: ruptured and aneurysm and abdominal

ISRCTN Register

14 results ruptured and abdominal and aneurysm 


\section{FEE D B A C K}

\section{IMPROVE trial, 21 October 2014}

\section{Summary}

The authors have misinterpreted the diagnoses of patients in the IMPROVE trial.

613 patients had a clinical diagnosis of ruptured AAA before CT scanning

10 patients had no AAA

45 patients had asymptomatic AAA \& other final diagnoses

22 patients had symptomatic non-ruptured AAA

(not 77 as cited in review)

536 patients had proven diagnosis of AAA rupture, of whom 35 died before AAA repair was started.

\section{Reply}

We agree we have misinterpreted the 77 participants that were randomised but did not actually have a ruptured abdominal aortic aneurysm, which was discovered at commencement of the intervention. We have amended the text in the locations where we discuss this aspect of the IMPROVE trial using the data supplied by Professor Janet Powell.

\section{Contributors}

Feedback: Prof Janet Powell, Chief Investigator IMPROVE trial, Imperial College London, UK

Reply: Mr Stephen Badger, Department of Vascular Surgery, Mater Misericordiae University Hospital, Dublin, Ireland Mrs Rachel Forster, Centre for Population Health Sciences, University of Edinburgh, Edinburgh, UK

Dr Denis Harkin, Belfast Vascular Centre, Royal Victoria Hospital, Belfast, UK

\section{Feeback, 13 June 2017}

\section{Summary}

We were pleased to see the updated Cochrane Review of "Endovascular Treatment for Ruptured Abdominal Aortic Aneurysm" by Badger et al. (DOI: 10.1002/14651858.CD005261). However, we hoped that there might be an opportunity to correct some of the inaccuracies, relating mainly to IMPROVE but also to some aspects of the AJAX and ECAR trials.

1 Page 9, Sensitivity analyses. The first sentence should start "Although all the participants in the IMPROVE trial had a clinical diagnosis of RAAA". In the second sentence one of the clauses should read " 45 had asymptomatic AAA and other final diagnoses".

2 Page 14 Open Conversion. The information regarding IMPROVE is incorrect. Currently it reads "IMPROVE study reported four out of the $316(1.3 \%)$ randomised participants". In fact, open conversion occurred in 5/186 EVARs (four in the endovascular strategy group and one in the open repair group) in the IMPROVE trial. Therefore the use of $1.3 \%$ is incorrect.

3 Page 14 Bowel ischaemia. The data for the IMPROVE trial, by randomized group, are given in the reference Sweeting et al 2015.

4 Page 15, Mortality and complications at 6 months or longer. As is evident from Sweeting et al 2015 and 2015 a, we hold all the data for AJAX, ECAR and IMPROVE. No one contacted us with a data request for the ECAR or AJAX trials. The mortality data to 5 years for AJAX, by randomized group, also are available in van Beek SC et al. Eur J Vasc Endovasc Surg 2015;49:661-668

5 Page 15 Quality of life. The authors appear to have missed the fact that the IMPROVE trial one year results provided EQ5D data at both 3 and 12 months (Eur Heart J 2015;36:2061-9, although the listing of authors is incorrect).

6 Page 28, Characteristics of included studies. The study aim of the trial is listed incorrectly. It should read "Study aim: to assess whether an endovascular strategy versus open repair reduces early mortality for people with suspected RAAA".

We would be pleased to help with amending these inaccuracies and they may have some bearing on the Discussion and Implications sections.

\section{Reply}

The authors have been invited to respond to the feedback

\section{Contributors}

Feedback:

Professor JT Powell MD, PhD, FRC Path, Imperial College London, UK, Dr Pinar Ulug, Imperial College London, UK 
WHAT'S NEW

\begin{tabular}{lll}
\hline Date & Event & Description \\
\hline 13 June 2017 & Feedback has been incorporated & Feedback received \\
\hline
\end{tabular}

\section{HISTORY}

Protocol first published: Issue 2, 2005

Review first published: Issue 1, 2007

\begin{tabular}{lll}
\hline Date & Event & Description \\
\hline 21 September 2016 & $\begin{array}{l}\text { New citation required but conclusions } \\
\text { have not changed }\end{array}$ & $\begin{array}{l}\text { New search run. One new study included. No new studies exclud- } \\
\text { ed. Text updated to reflect current Cochrane standards. 'Summa- } \\
\text { ry of findings' table added. No change to conclusions. }\end{array}$ \\
\hline 21 September 2016 & New search has been performed & $\begin{array}{l}\text { New search run. One new study included. No new studies exclud- } \\
\text { ed. }\end{array}$ \\
\hline 21 September 2016 & Feedback has been incorporated & Feedback addressed. \\
\hline 17 April 2014 & Feedback has been incorporated & Feedback received. \\
\hline 17 April 2014 & New search has been performed & $\begin{array}{l}\text { Searches rerun, three new studies included, two new studies ex- } \\
\text { cluded. }\end{array}$ \\
\hline 30 May 2008 & Amended & $\begin{array}{l}\text { Searches rerun, three new studies included, two new studies ex- } \\
\text { cluded. Review fully updated. Two new authors have joined re- } \\
\text { view team. Conclusions changed. }\end{array}$ \\
\hline
\end{tabular}

\section{CONTRIBUTIONS OF AUTHORS}

For the current update of this review, Stephen Badger and Rachel Forster performed study selection, quality assessment, and data extraction. Drafting of the review was performed by Rachel Forster with input from Stephen Badger and Denis W Harkin. Paul H Blair, Peter Ellis, and Frank Kee acted as arbitrators in the case of disagreements over inclusion and quality of studies.

For previous versions of this review, Marianne Dillon and Denis W Harkin performed the literature searches, identified all possible trials, considered them for inclusion, and assessed trial quality. Paul H Blair, Peter Ellis, Chris Cardwell, and Frank Kee acted as arbitrators in the case of disagreements over inclusion and quality of studies.

\section{DECLARATIONS OF INTEREST}

SB: None known.

RF: None known.

PHB: None known.

PE: None known.

FK: None known.

DWH: None known. 


\section{SOURCES OF SUPPORT}

\section{Internal sources}

- No sources of support supplied

\section{External sources}

- Chief Scientist Office, Scottish Government Health Directorates, The Scottish Government, UK.

The Cochrane Vascular editorial base is supported by the Chief Scientist Office.

- National Institute for Health Research (NIHR), UK.

This project was supported by the NIHR, via Cochrane Incentive Award funding (16/72/05) to Cochrane Vascular. The views and opinions expressed therein are those of the authors and do not necessarily reflect those of the Systematic Reviews Programme, NIHR, National Health Service (NHS), or the Department of Health.

\section{DIFFERENCES BETWEEN PROTOCOLANDREVIEW}

In order to reflect the nature of the diagnosis of ruptured abdominal aortic aneurysm, we rephrased 'clinical diagnosis of ruptured abdominal aortic aneurysm' to 'clinical and radiological diagnosis of ruptured abdominal aortic aneurysm'. We also clarified the 'Types of participants' section.

We added a new outcome, 'complications and mortality long term (longer than six months); we sought re-intervention rates for problems related to the ruptured abdominal aortic aneurysm as well as cause of death with or without re-intervention, that is device-related', as we expect these data will become available in the future.

We rephrased the outcome 'aneurysm exclusion' to 'endoleak', as this previously used term was vague and found to be misleading.

\section{N DEX TERMS}

\section{Medical Subject Headings (MeSH)}

Aortic Aneurysm, Abdominal [mortality] [ ${ }^{*}$ surgery]; Aortic Rupture [mortality] [ ${ }^{*}$ surgery]; Conversion to Open Surgery [statistics \& numerical data]; Emergency Treatment [ ${ }^{*}$ methods] [mortality]; Endoleak [etiology]; Endovascular Procedures [ ${ }^{*}$ methods] [mortality]; Hospital Mortality; Intestines [blood supply]; Ischemia [etiology]; Kidney Diseases [etiology]; Myocardial Infarction [etiology]; Postoperative Complications; Quality of Life; Randomized Controlled Trials as Topic; Respiratory Insufficiency [etiology]

\section{MeSH check words}

Humans 